\title{
TRANSITIONS INTO PERMANENT EMPLOYMENT IN SPAIN: AN EMPIRICAL ANALYSIS FOR YOUNG WORKERS*
}

\author{
J. Ignacio García-Pérez and Fernando Muñoz Bullón ${ }^{1}$
}

\begin{abstract}
We analyze the Spanish temporary workers' transitions into permanent employment and to what extent those who become unemployed are able to achieve a permanent job. Our focus is placed on the role of the individual's sequence of temporary contracts on the probability of moving from temporary into permanent employment. We apply multiplespell duration techniques to a longitudinal dataset of temporary workers obtained from Social Security records for the period 1996-2003. We basically find that even though transitions into permanent employment increase with tenure, temporary jobs do not constitute stepping stones towards permanent employment, since the probability of obtaining a permanent job decreases with repeated temporary jobs. Results also show that individuals with high duration of unemployment flow into permanent work less frequently.
\end{abstract}

Keywords: Employment and unemployment hazard rates, duration dependence, unobserved heterogeneity, labor market reforms in Spain

JEL Classification: J24, J62.

\footnotetext{
* The authors would like to thank participants at the XXXI Simposio de Análisis Económico (Oviedo, Spain). The usual disclaimer applies.

${ }^{1}$ Corresponding author at: Universidad Carlos III, Sección de Organización de Empresas, C/Madrid 126-

Getafe (Madrid), 28903 (Spain); fernando.munoz@uc3m.es. Tel: +34-91-624-58-42; fax: +34-91-624-57-07
} 


\section{Introduction}

In the mid-eighties, in order to fight against the high and persistent levels of unemployment, Spain enhanced the flexibility of its labor market by allowing employers to hire workers on a fixed-term basis. The main purpose of the new legislation was to lower layoff and discharge costs and thereby address the high unemployment rate by promoting hiring. The implications of increased job flexibility have been particularly acute in this country, where deregulation of temporary employment was undertaken without modifying the employment regulation of permanent workers (Bentolila and Dolado, 1994). Lower dismissals costs, and sometimes wages, under temporary contracts favoured employers' hiring of workers on fixed-term contracts ${ }^{1}$. As a result, temporary employment increased from around $10 \%$ in the mid-eighties to more than $30 \%$ in the early nineties. Nowadays almost $91 \%$ of all new registered employment contracts are temporary in Spain (García-Pérez and MuñozBullón, 2005a).

In this paper, we examine the dynamics of temporary workers' transitions to other labor force states. In particular, we analyze the extent to which temporary work facilitates the movement into regular (or permanent) work. The analysis is particularly important in Spain, where there is a general consensus that reduced wages, job stability, and advancement opportunities for temporary workers has promoted a class of secondary workers who can be best characterized as involuntary and permanently employed on a temporary basis (Segura et al., 1991; Bentolila and Dolado, 1994; Alba-Ramírez, 1997; Amuedo-Dorantes, 2000). In particular, the growth of temporary employment has raised many concerns regarding its capacity to act as a springboard towards permanent employment (Booth et al., 2002a). Thus, an important aspect of the use of temporary contracts is their pattern of promotion into regular contracts of indefinite duration. If at least some individuals holding temporary contracts are able to reduce their duration until regular work, then it may be sensible to stimulate the use of temporary work among such a group. On the contrary, if Spanish temporary employment displays few opportunities for advancement, targeted policy action is called for. The relevance of this issue from a policy point of view lies not only on the fact that policy makers and labour market analysts have become increasingly concerned about the growth of temporary employment in Europe ${ }^{2}$, but also on the fact that Spain represents an extreme experience in several labor market dimensions, such as its rate of unemployment, its employment protection legislation and its rate of temporary workers (see, in this respect, Güell and Petrongolo, 2007).

We use a longitudinal administrative data source which tracks the labor careers of workers whose initial contract was temporary in 1996 up to the year 2003. The empirical analysis is carried out separately for workers in three different occupational levels (skilled, semi-skilled and unskilled positions). We estimate a multiple-spell hazard model with competing risks. The model specifies the transition rates from temporary employment into unemployment, temporary or permanent employment, and

\footnotetext{
${ }^{1}$ For a detailed description of employment protection in Spain, see for example, Bover, García-Perea and Portugal (2000).

${ }^{2}$ The growing share of temporary employment in many European countries has raised concerns over the risk of labour market segmentation. Several studies have indicated the existente of a gap between the working conditions of permanent and temporary employees, particularly in terms of wages and working rights (OECD, 20002).
} 
also from unemployment into temporary versus permanent employment. Each transition rate is allowed to depend on observed and unobserved explanatory variables as well as on elapsed time spent in the current $\operatorname{state}^{3}$. Our results suggest that temporary work is more likely to become a trap than a bridge to permanent employment. In particular, controlling for unobserved heterogeneity is important in order to obtain clear estimates.

The analysis of the effect of repeated temporary contracts on the probability to find a permanent job has been the subject of several studies. For instance, Van Ours (2004) investigates locking-in effects of temporary subsidized jobs through a natural experiment in the Slovak labor market in the nineties. Booth et al. (2002b) study the labor market prospects of temporary workers in the UK (where temps represent $7 \%$ of male employees and $10 \%$ of female employees). Their results show that temporary employment is associated with lower wages, less specific training and lower job satisfaction in respect to permanent employment, though it is not associated with negative trajectories. Zijl et. al (2004), using a multi-state model and, applying the "time of events" approach, find that temporary jobs serve as stepping stones towards regular employment. Finally, Gagliarducci (2005) show evidence for the Italian labor market indicating that the probability of moving into regular employment decreases with job interruptions.

However, up to our knowledge, for Spain there are only a few studies on the transitions between temporary and permanent employment. For instance, Amuedo-Dorantes (2001) examines the determinants of Spanish conversions of temporary contracts into permanent ones using information on the composition of employment at the firm level. She finds that dismissal costs hardly affect contract conversions, which mostly respond to employment expectations and union pressure for increased employment stability. Most existing studies on the determinants of individual conversion rates use logit specifications (Toharia 1996, and Alba-Ramírez, 1998), which may be not very flexible when applied to the analysis of the dynamic path of transition rates. To our knowledge, duration studies on Spanish conversion rates are that of Amuedo-Dorantes (2000), Guiell and Petrongolo (2007) and Casquel and Cunyat (2005) ${ }^{4}$. Amuedo-Dorantes (2000) estimates transitions out of temporary employment using the Labor Force Survey and finds that conversion rates are very low, regardless of job tenure. Güell and Petrongolo (2007) use the same dataset to study the time pattern of permanent employment; they find that estimates deliver clear spikes at the legal limit, that higher conversion rates occur in cases where workers supposedly have higher outside options, and that conversion rates of temporary into permanent contracts increase with tenure. Finally, Casquel and Cunyat (2005) analyze whether the existence of observable and unobservable characteristics influences the transition rate to a permanent employment and conclude that in Spain temporary contracts do not play this role.

\footnotetext{
${ }^{3}$ Among the advantages of analyzing the dynamics of temporary and non-employment spells is that multi-spell data greatly facilitates the identification and estimation of the joint distribution of the unobserved heterogeneity variables (see Honoré, 1993, and van den Berg, 2001)

${ }^{4}$ García-Serrano (2004) also analyses whether workers with temporary contracts induces them to present a high employment exit rate. With the living and working conditions database (Encuesta de Calidad de Vida en el Trabajo) for the year 2001, he concludes that individuals under temporary contracts suffer worse labour conditions and face a greater employment exit rate, especially those with tenure lower than 18 months.
} 
This paper is organized as follows. Section 2 describes the Spanish institutional framework. Section 3 briefly presents the hypotheses under examination. Section 4 describes the data used. Section 5 presents the empirical model and its main results. We conclude in Section 6.

\section{The institutional framework}

Before 1984, Spanish legislation on labor contracts (contained in the Workers' Statute of 1980) assumed every contract to be an open-ended contract as a general case, whereas temporary contracts were intended to be used only for jobs whose nature were temporary (seasonal jobs, temporary substitution of permanent workers, etc). In 1984, however, the Spanish government introduced the first reform designed to reduce dismissal costs - since then, they require lower severance payments than permanent contracts when the contract terminates ${ }^{5}$ - and to liberalize the use of temporary contracts: it eliminated the requirement that the activity associated with the job were of temporary nature. As a result of this reform, the proportion of employees under temporary contracts increased from 10\% during the 1980's to over $30 \%$ in the early 1990 's. These contracts can be signed for a period between a minimum of six months and a maximum of three years. After three years, the contract cannot be renewed, and the worker must be either fired or be offered a permanent contract by his current employer. In the former case, the employee cannot hire any other worker for the job.

Between 1985 and 1994, over 95\% of all new hires were employed through temporary contracts and the conversion rate from temporary to permanent contracts was only around 10\% (Güell and Petrongolo, 2007). Thus, the main concern with the liberalization of temporary contracts after 1984 was that it generated a huge segmentation between unstable low-paying jobs and stable high-paying jobs, without appearing to reduce unemployment.

Shifting direction in light of these concerns, in 1994 new regulations limited the use of temporary employment contracts to seasonal jobs. In addition, the 1994 reform slightly relaxed dismissal conditions for permanent contracts. In particular, the definition of fair dismissals was widened by including additional "economic reasons" for them. In practice, approval for dismissals under "economic reasons" continued to be granted mainly when there was an agreement between employers and workers and labor courts continued to rule most dismissals as unfair, so that dismissal costs on permanent contracts did not change much.

In practice, however, employers continued to hire workers under temporary contracts for all types of jobs and not just for seasonal jobs. This perceived ineffectiveness of the 1994 reform led to a new reform in 1997, which was eventually extended in 2001. As with the 1994 reform, the goal of the 1997 and 2001 reforms was to reduce the use of temporary contracts. It created a new type of permanent contract, with lower severance costs in case of unfair dismissal (33 days per year of seniority) and with fiscal incentives in the fist two years of the contract (i.e., reductions of employers' payroll taxes). However, rather than trying to limit the use of temporary contracts by further possibly ineffective regulation, these new reforms increased the incentives for firms to

\footnotetext{
${ }^{5}$ In particular, temporary workers are entitled to 8 days per year of seniority based on the salary whereas permanent workers may obtain up to 45 days if dismissal is found to be unfair.
} 
hire workers from certain population groups under permanent contracts ${ }^{6}$. This reform led to a sharp and sustained increase in the number of permanent contracts for workers in some of these affected groups. Finally, the 2001 reform extended the use of the new permanent contracts created in the 1997 reform to other groups of workers, and introduced a new severance payment of 8 days of wages per year of seniority in temporary contracts not renewed.

\section{Hypotheses: the transitions under examination}

To what extent and how does accumulating temporary jobs affect the probability of finding a permanent job? There are at least two reasons why temporary employment might represent a "springboard" to permanent employment. On the one hand, according to the matching approach, firms may use temporary contracts as a screening device in order to identify the best matches: in this case, more-able workers might signal their type by making themselves available for screening under temporary contracts. In this sense, workers who are able to find a temporary job provide a signal of their quality to potential employers, since being on a temporary contract means that the worker is willing to take a job (rather than, for instance, rely on unemployment benefits). Therefore, temporary job experience may be informative about the ability and motivation of the individual ${ }^{7}$. We would then expect that the rate of transition from a temporary contract to an open-ended contract would decrease as time goes by, since employers will use an individual's labor market history to sort good workers from bad workers and they might perceive (rightly or wrongly) that a previous history of multiple temporary contracts is likely to result in some loss of skills.

On the other hand, following the human capital approach, being employed under a temporary contract allows the worker the acquisition of human capital (either general or specific) which would positively influence the probability of acquiring a permanent status - in addition to social contacts and information on permanent vacancies, which may allow the individual to deepen his attachment to the labor market, and to search more effectively for more desirable jobs. Moreover, as explained in the literature on career interruption ${ }^{8}$, unemployment spells following terminations of temporary contracts would make the individual incur not only the permanent loss of firm-specific human capital, but also the deterioration of general skills (Gregory et al., 2001).

However, temporary employment may also be a "trap" of endless precariousness especially as duration in the temporary contract increases. On the one hand, a temporary contract may also serve as a signal as to the lack of alternatives (especially in case that the employer believes that the temporary worker has already been screened by other employees). On the other hand, due to the high turnover usually associated with temporary work experiences, temporary work may be associated with limited acquisition of human capital. Finally, as search intensity for an open-ended job is expected to reduce with the duration in the non-permanent state, we expect the exit rate

\footnotetext{
${ }^{6}$ In particular, the 1997 reform reduced dismissal costs for unfair dismissals by about $25 \%$ and payroll taxes between $40 \%$ and $90 \%$ for newly signed permanent contracts and for conversions of temporary into permanent contracts after the second quarter of 1997 for workers under 30 years-old, over 45 years-old, the long-term unemployed, women under-represented in their occupations, and disabled workers (see, in this respect, Kugler et al., 2003)

${ }^{7}$ Indeed, some studies have shown that employers use atypical contracts as a way of screening for permanent jobs (Storrie, 2002; Housman et al., 2003).

${ }^{8}$ See Mincer and Ofek, 1982.
} 
from a temporary to a permanent contract to be negatively associated with such duration.

\section{Data and descriptive statistics}

The sample used in this paper is drawn from the Spanish Social Security records and comes from two different random samples. The first sample is a one per cent of the population, who were either employed or unemployed on the first of January, 1990 (77398 individuals). The second sample is another one per cent of individuals, who were either employed or unemployed on the 31st of December, 2003 (116990 individuals). The data provided includes information about the complete labor market history of these two samples of workers. Moreover, it offers information about the age and gender of the workers, the occupation held ${ }^{9}$, the dates when the employment spell starts and ends, the reason for the termination of the spell (voluntary quit, dismissal or retirement), the Spanish province where the employment spell took place, an identifier of whether each employment spell is accomplished through a Temporary Help Agency or not, the type of contract held by the worker, and, finally, whether the individual is receiving or not unemployment benefits.

From this initial dataset, given that our interest is on labor careers starting out of temporary contracts and that the variable collecting the type of contract is only reliable from the second half of the nineties, we select only individuals whose initial contract in 1996 is a temporary one. In order to minimize the initial sample heterogeneity, we make another restriction: we select workers who, at the time of the initial temporary contract, were aged between 16 and 25 years-old. This allows us to keep a final sample of individuals who can be considered very similar a priori and whose following achievements in the labor market can then be attributed, after controlling for observable and unobservable heterogeneity, only to their career. We have also eliminated observations with missing information on any variable used. Moreover, we have removed workers in specific regimes like Agriculture or Self-employed workers. This leaves us with a sample of 20,598 individuals.

There are two main advantages of using Social Security records for the analysis of labor careers. On the one hand, information is available on all jobs held by the individual during a certain interval of time; in particular, the longitudinal character of the database makes it possible to follow the same individuals from 1996 up to the end of 2003, and, therefore, to observe their career progress or decline along time. We keep every temporary contract in the dataset separately, allowing for workers to move from one job to the following one. On the other hand, we can accurately measure the duration between the start of a temporary job until the moment at which the individual moves to a permanent or a new temporary job or becomes unemployed. And, subsequently, we can also accurately measure the duration between the start of unemployment and the moment at which the individual moves into temporary or permanent employment. Given the scarcity of observations beyond 42 (30) months for employment

\footnotetext{
9 The occupation indicates a level in a ranking determined by the worker's contribution to the Social Security system. It is related to the individual's qualification level, since it comprises the required qualification level for the job. However, it does not comprise the workers' actual level of qualification. For instance, an individual working in the lowest occupation may well be in possession of a high academic degree (see, in this respect, García-Pérez and Muñoz-Bullón, 2005a, 2005b).
} 
(unemployment) spells, we have treated observations beyond this duration (respectively) as artificially right-censored.

Thus, there is only one initial state (a temporary contract, TC) and then the entry into subsequent spells is completely internalized. The initial spell includes individuals with the main types of temporary contracts: casual, work-experience (practice), per task, training or interim contracts ${ }^{10}$. Our analysis is separately done for three sub-samples of individuals, defined according to the occupation held: high, intermediate and low occupational groups. ${ }^{11}$ Figures $1.1,1.2$ and 1.3 show the labor market states for each of these three groups (up to their third transition). As can be observed, there are three possible destination states out of the initial temporary contract: Unemployment (U), Temporary contract (TC) and Permanent contract (PC) ${ }^{12}$. The transition to permanency allows us to test the stepping-stone hypothesis whereas the transition to other states will be useful to contrast whether temporary contracts are dead-end jobs by themselves. With respect to the exit from unemployment, there are two possible transitions: Temporary contract (TC) or Permanent contract (PC). Thus, those figures present five possible transitions: TC-U, TC-TC, TC-PC, U-TC and U-PC. We consider the PC state to be an absorption state, meaning that every spell after the transition to $\mathrm{PC}$ is removed from the sample.

The most frequent transition out of the initial temporary contract is into unemployment, especially for the Low and Intermediate qualification groups. The second most empirically observed transition is into another temporary contract. The transition into a PC state positively depends on the qualification level $(9.7 \%$ for the High qualification group, $7.8 \%$ for the medium qualification group, and $6.5 \%$ for the Low qualification group). Finally, transitions from temporary jobs to permanent jobs are not frequent, even less than transitions from unemployment to permanent employment. These numbers are roughly consistent with earlier findings in Spain (see Kugler et al, 2003, or Güell et al., 2007). As a first impression, therefore, temporary employment is unlikely to serve as a stepping-stone towards regular work.

We are also interested on the effect of duration in a determined state (either TC or Unemployment) on the likelihood of attaining regular employment —and not only on transitions into permanent employment. For this purpose, Figures 2.1, 3.1 and 4.1 present monthly Kaplan-Meier estimates of such transitions for each qualification group considered. These empirical hazard functions collect the proportion of individuals leaving the TC state at each moment in time, given that they have been temporarily employed until that moment (Lancaster, 1990). For any qualification group considered, the probability of exiting from temporary employment into any destination state declines with tenure, and (as expected from the commented-above transitions) the most likely aftermath of a temporary job is a period of unemployment, followed by obtaining a new temporary contract. Moreover, exit rates into unemployment and into another

\footnotetext{
${ }^{10}$ See the Appendix for definitions for each type of temporary contract. In order to know more details on each type of contract, see the Guía Laboral, elaborated by the Ministerio de Trabajo y Asuntos Sociales, which is freely available in the following web page: http://www.mtas.es

${ }^{11}$ The specific categories within each group are detailed in the Appendix. See, for instante, García-Fontes and Hopenhayn (1996), García-Pérez (1997), or García-Pérez and Muñoz-Bullón (2005a, 2005b), who use a similar classification.

${ }^{12}$ In the transitions TC-TC and TC-PC, the possible unemployment period in between the two contracts has to be no longer than 15 days. The transition TC-U implies that the initial temporary contract finishes and the subsequent unemployment spell lasts for more than 15 days.
} 
temporary contract are very high early in the temporary job; the former reaches the maximum in the Medium qualification group (31.45\%) while the latter has its maximum in the High qualification group (18.09\%). The exit rate into a permanent job is, however, minuscule, independently of the qualification group considered. It is noteworthy that the hazard rates from TC rise to peaks in months $6,12,24$ and 36. These peaks show that temporary contracts are very likely to finish at each of these particular months. Given that no special reason can be adduced to explain why individuals should be dismissed at those months, these duration effects are likely due to temporary contract terminations, since they are usually signed for these specific durations. Similar results are obtained in previous studies (see, in particular, GarcíaPérez and Muñoz-Bullón, 2005a, or Güell and Petrongolo, 2007).

Empirical hazard rates from unemployment are shown in Figures 2.2, 3.2 and 4.2. As can be observed, exiting into a temporary contract is much more likely when compared to the alternative (permanent employment). The hazard rate into a TC is substantially high at the beginning of the unemployment experience, reaching levels above 10 percent during the first eleven months (for any qualification group). It shows a peak around the $10^{\text {th }}$ month, and falls very quickly from then on, remaining at levels slightly above 5 percent. However, the likelihood of entering into a regular job remains basically flat and shows no duration dependence.

Descriptive statistics are provided in Tables 1-4. Table 1 shows the types of temporary contracts in the sample for each qualification group considered (high, intermediate and low occupational groups). As can be observed, most of TC spells are based on per task and casual contracts, while work-experience, training and interim contracts do only account for approximately $11 \%$ of TC spells. Work-experience and training contracts are the ones having longer tenure, while interim, casual and per task are the shortest ones. The proportion of TC spells where dedication is part-time is the highest in the Medium qualification group (37.31\%). Finally, by looking at the first spell, for the High qualification group, the most remarkable finding is that the weight of work-experience contracts substantially increases and that of interim contracts reduces, while the weight of the training contracts increase in the Low group.

As Table 2 shows, most of workers in the High qualification group suffer less than two spells of unemployment $(50.6 \%)$ and three or less TC spells $(61.5 \%)$. For the remainder qualification groups, it is more common to observe workers with a higher number of both unemployment and TC spells. For instance, in the Medium (Low) group, 43.8\% (38.8\%) of workers suffer less than two unemployment spells, and 56.3\% (52.1\%) experience three or less TC spells. Moreover, as the number of TC spells increase, it is more likely to observe a higher incidence of unemployment spells. Thus, repeated temporary contracts frequently imply unemployment spells.

Table 3 shows that at relatively short durations, TCs are more likely to end up into unemployment. The likelihood of another TC, though not as large as that of ending up in unemployment, is, as well, rather large for short tenure in TC. As duration proceeds, the probability of unemployment and that of another TC substantially reduces, while the chances of permanent employment increase ${ }^{13}$. In addition, the length of transitions from

\footnotetext{
${ }^{13}$ This table shows evidence of some TCs continuing beyond the legal limit of three years. This may be attributed either to the fact that there may be imperfect compliance by employers shortly after the threeyear limit, or measurement error (see, in this respect, Güell and Petrongolo, 2007).
} 
TC to PC is longer than from TC to TC, and especially from TC to Unemployment. This may imply that employers generally use temporary contracts as a probation period and that "good" matches (in terms of renewal into PC or TC) last longer.

Finally, Table 4 shows descriptive statistics at the time of the first TC considered. In the high and medium qualification groups, workers are predominantly females $(60.1 \%$ and $67.0 \%$, respectively), while workers are essentially men in the low qualification group $(60.3 \%)$. The higher the qualification group considered, the older the worker is, although on average, differences as regards age are not substantial on average. In addition, only around one fifth of workers are initially hired through a Temporary Help Agency.

\section{Econometric specification}

In order to study the hazard rate for both employment and unemployment, we use a discrete-time duration model (See Lancaster, 1990, or Jenkins, 1995 for the basic features of such models). In general, the hazard rates we will estimate are given by the following conditional probability:

$$
\phi(t)=\operatorname{Pr}(T=t \mid T \geq t)
$$

where $T$ is a discrete random variable denoting either employment or unemployment duration. Following Bover et al. (2002b) and García-Pérez (1997), we use a logistic distribution to model the hazard rates, so that the two conditional exit rates can be written as follows:

$$
\begin{aligned}
& \phi_{U}^{j}(t)=F\left(\theta_{0}^{j}(t)+\theta_{1}^{j}(t) x(t)\right) \\
& \phi_{E}^{k}(t)=F\left(\gamma_{0}^{k}(t)+\gamma_{1}^{k}(t) x(t)\right)
\end{aligned}
$$

where $x(t)$ denotes the vector of explanatory variables, some of them varying with spell's duration, $t, j$ is a counter for the two possible exits from unemployment, TC and $\mathrm{PC}$, and $k$ is a counter for the exits from a temporary contract (U, TC and PC). $\theta_{0}^{j}(t)$ and $\gamma_{0}^{k}(t)$ represent the additive terms of the duration dependence in the hazard rates that we will estimate in the most general way as possible. Finally, $\theta_{1}^{j}(t)$ and $\gamma_{1}^{k}(t)$ are the coefficients for the explanatory factors which in general depend on duration.

As we are considering a competing risk framework, the exit from a given state, unemployment or temporary employment, has to be specified as:

$$
\begin{aligned}
& \phi_{U}(t)=\sum_{j=1}^{J_{U}} \phi_{U}^{j}(t) \\
& \phi_{E}(t)=\sum_{j=1}^{J_{E}} \phi_{E}^{j}(t)
\end{aligned}
$$

Furthermore, in order to avoid the known spurious duration dependence in the hazard rate, generated by the presence of unobserved factors, we control for unobserved 
heterogeneity. Hence, we will estimate the unemployment and employment hazard rates simultaneously and assuming that unobserved heterogeneity follows a discrete distribution function with different mass points (as used in Heckman and Singer, 1984). In particular, we consider the case of a two-mass-point distribution function, and we estimate the model by maximum likelihood.

The likelihood function considers the three possibilities of censoring present in our data. Firstly, unemployment duration may be censored, in which case employment duration is not observed. Secondly, we may have a completed unemployment spell and a censored employment one. And finally, both unemployment and employment spells may be completed ones, that is, not censored. The individual likelihood function with unobserved heterogeneity can easily be constructed as follows:

$$
\begin{aligned}
L_{i}(\eta)= & {\left[\prod_{s=1}^{t_{u}}\left(1-\phi_{u_{i}}(s, \eta)\right)\right]^{d_{u_{i}}}\left[\phi_{u_{i}}\left(t_{u}\right) \prod_{s=1}^{t_{u}-1}\left(1-\phi_{u_{i}}(s, \eta)\right) \prod_{s=1}^{t_{e}}\left(1-\phi_{e_{i}}(s, \eta)\right)\right]^{\left(1-d_{u_{i}}\right) d_{e_{i}}} } \\
& {\left[\phi_{u_{i}}\left(t_{u}\right) \prod_{s=1}^{t_{u}-1}\left(1-\phi_{u_{i}}(s, \eta)\right) \phi_{e_{i}}\left(t_{e}\right) \prod_{s=1}^{t_{e}-1}\left(1-\phi_{e_{i}}(s, \eta)\right)\right]^{\left(1-d_{u_{i}}\right)\left(1-d_{e_{i}}\right)} }
\end{aligned}
$$

where $t_{u}$ and $t_{e}$ represent unemployment and employment durations, and $d_{u i}$ and $d_{e i}$ are two indicators that allow us to distinguish between censored and completed unemployment and employment spells respectively. ${ }^{14}$ The log-likelihood function with unobserved heterogeneity then takes the form:

$$
\ln L=\sum_{i=1}^{N} \ln \int L_{i}(\eta) d F(\eta)
$$

where $F(\eta)$ is the previously described mass point distribution function..

\section{Results}

Tables 6, 7 and 8 report the results obtained from a simultaneous estimation of hazard rates for both employment and unemployment durations controlling for unobserved heterogeneity. The competing risks hazard model is used to examine the likelihood that workers exit temporary employment and (1) enter unemployment; (2) enter a new temporary job; (3) enter permanent employment; (4) continue in the current temporary job. Simultaneously, we estimate the likelihood that temporary workers who enter unemployment exit into (1) a new temporary job; (2) a permanent job; or (3) continue unemployed. As explained above, as regards unobserved heterogeneity, we have assumed that it can be summarized by a discrete two-mass point distribution function.

Although our dataset does not contain variables related to the individual's educational attainment, ${ }^{15}$ it does provide information related to the required level of qualification for the job (see Table A in the Appendix). Different levels of qualification are expected to

\footnotetext{
${ }^{14}$ For the ease of the exposition, we are not writing in this expression the specific alternative exits from each state.

${ }^{15}$ The education level is expected to enhance productivity and a worker's outside options.
} 
imply different employment and unemployment prospects for individuals. This will affect their outside options and thus their bargaining power on temporary jobs ${ }^{16}$. We thus carry out estimations separately for three sub-samples of individuals, defined according to the occupation held (see Section 3). Figures 5.1 (5.2), 6.1 (6.2) and 7.1 (7.2) show the predicted employment (unemployment) hazard rates, at mean of covariates for each qualification group and by controlling for the presence of unobserved heterogeneity.

Apart from the explanatory variables described above, we control for the economic cycle through the growth rate of employment in the region where employment/unemployment takes place and the regional unemployment rate in order to account for geographical differences. Moreover, duration-dependence has been taken into account through the inclusion of a polynomial in $\log (t)$ in the specification of each hazard rate. In addition, since Kaplan-Meier estimates for the employment hazard indicate that the likelihood of exiting from employment is significantly higher at the sixth, twelfth, twenty-fourth and thirty-sixth month ${ }^{17}$ (see previous section), the specification of the employment hazard rate includes dummy variables indicating whether or not the individual is on-the-job at such months. Finally, the specification for unobserved heterogeneity is additive in the hazard rate and similar for all possible exits except for the one to a permanent contract where we allow for a shifter parameter $\left(\theta_{2}\right.$ in $\phi_{U}(t)$ and $\gamma_{2}$ in $\left.\phi_{E}(t)\right)$ in order to test whether such heterogeneity is making such exit systematically different to the alternative ones.

As regards the transitions out of employment, the dummies describing employment durations of $6,12,24$, and 36 months present a positive and very significant effect on the hazard rates, independently of the qualification group considered. As expected, therefore, temporary contracts end more likely at such durations than otherwise. As regards the transition into permanent employment, these results underlie the fact that firms may be converting temporary contracts into permanent ones, once the legal limit for the temporary contract has been reached. In addition, as regards unobserved heterogeneity, the estimated distribution shows the existence of two different types of individuals, one of whom (Type II) has much lower employment hazard rates (see Figures 5.1, 6.1 and 7.1, respectively for each qualification group). The effect of unobserved heterogeneity in the exit from TC to a PC is estimated to be much lower (the coefficient $\gamma_{2}$ is non-significant for the highly skilled and less than 0.5 in the other two groups). Hence, such unobserved component is affecting basically the exit to nonpermanent positions.

As shown in Figures 5.1, 6.1 and 7.1 - which reflect the duration dependence of the employment hazard rate- the peaks are clearly reflected in the corresponding predicted hazards. Moreover, as expected, the predicted hazard at most durations is higher for higher qualified workers than for the lowest qualified. However, the spikes at the $36^{\text {th }}$ month are relatively more important for the lowest-qualified than for the highestqualified ones. The fact that the time pattern of transitions into permanent contracts is lower for the lowest-qualified than for the highest-qualified is sensible may be given by the fact that the former group tend to occupy more productive job matches, which are

\footnotetext{
${ }^{16}$ In particular, skilled workers have lower unemployment rates than the less-skilled (see Dolado et al., 2002).

${ }^{17}$ Other studies (see, for instance, García-Pérez and Muñoz-Bullón, 2005a) also show evidence in this respect.
} 
thus more likely to be converted into permanent ones before the legal limit. Moreover, one can also think that the lowest-qualified are in a weaker bargaining position than the highest-qualified, as they may be more easily replaced.

One might expect that workers who accept a temporary job are initially strongly attached to that job, for instance, for contractual reasons. In some sense, this is true, since the negative estimated effect for duration dependence is reversed as tenure in the temporary job increases. As shown in Figures 5.1, 6.1 and 7.1, the predicted transition into regular employment increases after a period of eight months ${ }^{18}$ (as well as the transition into a new temporary job and into unemployment). This effect applies for the three sub-groups of workers, including the ones with a relatively weak labor market position (the lowest-qualified). This result implies that the probability of ending as unemployed, of receiving another temporary contract or of finding a permanent contract decreases during the initial months of temporary employment, but increases thereafter. Thus, in relation to permanent employment, temporary employment initially presents a temporary penalty effect, since this negative impact disappears for long enough duration in employment. A likely interpretation for this result is that sufficiently long experiences of employment increase worker's human capital, and this fact may help him/her to find a permanent job (compared to workers whose tenure in temporary employment is shorter). Apparently, employers may prefer individuals who have occupied a temporary job for enough time, given that this may constitute a positive signal. An increasing size of the social network among temporarily employed workers may also explain this. In addition, as the temp contract goes on, given its fixed-term nature, the worker may increase search intensity. This may also explain the observed positive effect on the job finding rate.

Finally, with regard to the transition from TC to PC, note how the hazard rate is rather stable even during the first months of tenure. Thus, most workers are transferred to permanent jobs at peak months. That is, when there is no other way to hold them. This establishes a difference with respect to the transitions from a temporary contract to another temporary contract: these transitions are also larger at the first months, but then they decline and eventually increase as duration lengthens (especially for the Type Iworker).

As regards the transitions out of unemployment (last four columns in Tables 5, 6 and 7) the probability of either finding a temporary or a permanent contract declines with unemployment duration. Note how the likelihood of permanent (or even temporary) employment substantially reduces during the first months in unemployment (Figures 5.2, 6.2 and 7.2). These results are consistent with Kaplan-Meier estimates commentedon above. However, contrary to duration-dependence for employment transitions, this negative effect of duration dependence is not reversed ${ }^{19}$. This implies that time spent in unemployment presents a strong negative impact on the likelihood of re-entering into employment (either through a temporary or a permanent employment). Thus, the more time goes by, the higher the locking-in effect of unemployment, since the latter causes the transition rate into regular work to be lower as time passes. We interpret this result in light of human capital theory: an unemployment spell not only precludes the accumulation of work experience, but may also bring about the deterioration of general skills (Gregory et al., 2001) and an individual's psychological well being (Goldsmith et.

\footnotetext{
${ }^{18}$ A similar finding is obtained by Zijl et al., 2004, pp. 14.

${ }^{19}$ The only exception is the transition into a temporary contract for the Low qualification group.
} 
al, 1996, 1997) ${ }^{20}$. Note also that from unemployment, the rate into temporary work is much larger than the rate into permanent work. This fact, together with the fact that the rate of flowing into regular employment in succession to a temporary job is similarly quite low, provides evidence on the non-existence of a stepping-stone effect.

As regards the presence of unobserved heterogeneity, for transitions out of unemployment, the estimated distribution function shows the existence of two different types of workers, one of whom (Type II) has lower unemployment hazard rates. The estimated model allows for a differential effect of such unobserved heterogeneity over the exit from unemployment to a TC or to a PC. We find that this effect is significantly larger than 1 for the High qualification group, and lower than 1 in the other two groups. Hence, the difference between the two types is larger in the exit to a permanent job for those highly qualified (Type II individuals have a substantially low exit probability from unemployment, especially to a permanent job). In the other two qualification groups, the exit to a PC is almost the same for the two types of workers.

It is important to note that individual background previous to current $\mathrm{TC}$ spell is relevant for explaining the transitions across labor careers. In particular, the chance of transiting into a permanent job (independently of whether the point of departure is either a TC or an unemployment spell) reduces as the number of previous contracts is larger. On the contrary, a higher number of previous temporary contracts helps the worker to find another temporary contract. Thus, moving from one TC to another TC is relatively easy but moving to a PC is more difficult the larger is the number of temporary contracts. Hence, the recurrent use of temporary employment has a substantial detrimental effect, since it deteriorates employment prospects in terms of the likelihood of exiting out of temporary employment. Moreover, even though a worker has a chance of moving from TC to PC and this chance increases with the time spent in a temporary job (as shown in previous Figures), for those who fail the probability of being promoted decreases with the next TC contracts. This reduction is due not only to repeated TC experiences, but also to interruptions in-between (which particularly penalize the transition into a stable job).

As expected, the time spent previously in unemployment has a negative effect in order to find a temporary job (and a non-significant effect in order to find a permanent job). However, it has a positive effect in order to become unemployed again. This result is reasonable to the extent that — since productivity is imperfectly observable - the likelihood of exiting from unemployment towards a temporary job will be lower if the employer takes a past history of unemployment as signalling low productivity. On the contrary, the larger tenure in the previous job is, the larger is the likelihood of exiting out of a TC into a PC (though only for the high qualification group), and the lower is the likelihood of moving into a TC or into unemployment. Thus, previous employment experience helps workers attain regular employment in case of high-qualified workers, independently of current tenure in the temporary job. This finding is consistent with dual labor market theory since skills (captured by tenure at the job) have a negative effect on the propensity to be employed in the secondary market (temporary job) relative to the primary market (permanent job). A 1-unit increase in tenure slightly increases by $1.6 \%$ the individual's likelihood of being permanently employed versus continuing under a temporary contract for the High qualification group. Moreover, ${ }^{20}$ Excellent analyses on the relationship between psychological capital and wages can be found in
Goldsmith et al., 1995, 1996 and 1997). 
during a spell of unemployment, the longer previous tenure is, the higher is the likelihood of re-entering into employment (either a TC or a PC). A possible interpretation of this result is that employers are likely to regard previous long employment experiences as positive signals in order to screen individuals for permanent positions or to hire unemployed individuals under a temporary contract.

The type of temporary contract held in the TC spell is another relevant determinant of the transitions. Having a casual — for the high qualification group - and an interim contract - for the medium and low qualification groups - increases the probability of achieving a permanent contract. On the other extreme, per-task contracts present a detrimental effect on the movement into regular employment (though this negative impact is non-significant for the High qualification group). As regards individuals who are currently unemployed, a previous job under a work-experience contract helps them enter into a permanent job (independently of the qualification group considered). Casual contracts also present a positive impact in the transition into regular employment (although being marginally significant for individuals belonging to the High qualification group). Finally, individuals on part-time work have non-significantly different transition rates into regular work than workers on full-time work ${ }^{21}$.

As regards demographic variables, for a male temporary worker the probability of achieving a permanent contract does not significantly differ from women in the High qualification group, while they are in a disadvantaged position (relative to women) in the two remainder groups. Age has a positive effect on the likelihood of transiting from TC to another job (either another TC or a PC), and a significant negative effect on the likelihood of entering into unemployment in the highest qualification group. As regards transitions from the unemployment state, age also exerts a positive impact (when significant) into another employment (under either a TC or a PC). These results for age are most probably related to the fact that older workers have more firm-specific human capital, which is highly valued by employers. In addition, it is a fact that younger workers are more willing to move from jobs (and employers) for improving their job match, even though this may imply an experience of unemployment, and eventually settling in a more stable career path (Jensen et al., 1999).

We find also that, out of a TC spell, the unemployment rate has a negative impact on the transitions into a PC. This may be attributed to the fact that when the unemployment rate is high, firms might keep on searching for better employees and so the probabilities that a worker is renewed or converted into a permanent job are lower. A lower unemployment rate implies better outside opportunities for temporary workers in search for better jobs. It enables them to more credibly threat their employer in case of low conversion rates. The unemployment rate also inflicts a negative impact as regards the exit from unemployment into a new job. On the contrary, the growth employment rate exhibits the opposite impact to that associated with the unemployment rate, both on the hazard out of a TC and on the hazard out of unemployment

Finally, the worker's Unemployment Benefits status is included in the estimation of the exit from unemployment as a dummy that indicated whether or not the individual receives contributory benefits. This dummy obtains the expected negative sign, for any

${ }^{21}$ Other studies have found that full-time employment has a positive effect on the likelihood that temporary workers become employed on a permanent basis. See, for instance, Amuedo-Dorantes (2000), pp. 323. 
qualification group considered. In addition, results show a large and statistically significant increase in permanent employment probabilities after 1997. This trend exists for both periods: 1997-2000 and 2001-2003. However, the trend is stronger for the former period and then, in spite of continuing positive and significantly different from zero, reduces from 2001 onwards. These findings are consistent with the evidence provided on permanent conversion rates in previous studies in $\operatorname{Spain}^{22}$. Thus, we can conclude that the reforms have basically strengthened the incentives to permanent conversions of temporary contracts.

\section{Summary and conclusions}

In this paper, we have investigated the transition from unemployment and temporary work to more stable positions. Our focus has been especially placed on the role of the sequence of temporary contracts on the probability of moving from temporary into permanent employment.

For this purpose, we have applied multiple-spell duration techniques to a longitudinal data set of temporary workers obtained from Social Security records for the period 1996-2003. The dataset contains multiple spells in labor market states for three different qualification groups of individuals. Our results show that, even though transitions into permanent employment increase with tenure, temporary jobs do not constitute stepping stones towards permanent employment, especially the larger the number of accumulated temporary contracts is, since the probability of obtaining a permanent job decreases with repeated temporary jobs. Moreover, the empirical evidence in this paper shows that the conversion rate from temporary to permanent employment is very low in Spain. In fact, having obtained a temporary job means that the transition rate into permanent work is not higher than the one from unemployment. Moreover, our results also show that individuals with high duration of unemployment flow into permanent work less frequently.

Our analysis, apart from the academic interest, becomes relevant from a policy perspective. Although the Spanish government has subsidized since 1997 the conversion of temporary contracts into permanent ones, it seems that such a decision is not being currently adopted more widely than before (see García Pérez and Rebollo, 2007 , for an evaluation of such a policy). Hence, it seems that in order for firms to hire workers on a permanent basis, apparently something else (apart from reducing the cost associated with the hiring permanent workers) is needed: one potential policy measure would consist of addressing more directly workers' productivity at the firm.

\footnotetext{
${ }^{22}$ Kugler et al. (2003) show that the 1997 reform led to a sharp and sustained increase in the number of permanent contracts for workers in some affected groups. And the 2001 reform, which became effective in January 2001, essentially extended de 1997 reform, but applied lower subsidies for some contracts signed in 1999.
} 


\section{References}

Abbring, J.H. and G.J. van den Berg (2003). "The non-parametric identification of treatment effects in duration models", Econometrica, vol. 71, no. 5, pp. 1491-1517.

Abbring, J.H. and G.J. van den Berg (2004). "Analyzing the effect of dynamically assigned treatments using duration models, binary treatment models, andpanel data models", Empirical Economics, vol. 29, pp. 5-40.

Alba-Ramírez, A. (1997). "How Temporary is Temporary Employment in Spain?", Working Paper 97-14, Economics Series 08, Universidad Carlos III de Madrid.

Alba-Ramírez, A. (1998), "How Temporary is Temporary Employment in Spain?", Journal of Labor Research, 19, pp. 695-710.

Amuedo-Dorantes, C. (2000), "Work transitions into and out of involuntary temporary employment in a segmented market: evidence from Spain", Industrial and Labor Relations Review, vol. 53, no. 2, pp. 309-25.

Bentolila, S. and Dolado, J.J. (1994). "Labor Flexibility and Wages, Lessons from Spain", Economic Policy, no. 18, 54-99.

Booth, A., J.J. Dolado and J. Frank (2002a), "Symposium on temporary work. Introduction", The Economic Journal, F181-F188.

Booth, A.L., Francesconi, M., Frank, J. (2002b). "Temporary jobs: stepping stones or dead ends?", The Economic Journal, 112, 189-213.

Bover, O., García-Perea, P. and Portugal, P. (2000). "Labor market outliers: Lessons from Portugal and Spain”, Economic Policy, 31, pp. 381-428.

Bover, O. and Gomez, R. (2004). "Another Look at Unemployment Duration: Exit to a Permanent vs. a Temporary Job", Investigaciones Económicas, vol. 28-2, 285-314.

Casquel, C. y Cunyat, A. (2004): "The Dynamics of Temporary Jobs: Theory and some Evidence for Spain", mimeo.

D'Addio, A.C. y Rosholm, M. (2005). "Exits from Temporary Jobs in Europe: A competing risks Analysis, Labor Economics, 12, pp.. 449-468.

Dolado, J.J., Jansen, M., Jimeno, J.F. (2002). “A Matching Model of Crowding-Out and On-the-job Search (with an application to Spain), CEPR Discussion Paper 3466.

Gagliarducci, S. (2005). "The dynamics of repeated temporary jobs", Labor Economics, 12, 429-448.

García-Pérez, J. I. (1997), "Las Tasas de Salida del Empleo y el Desempleo en España (1978-1993)", Investigaciones Económicas, Vol. 21, pp. 29-53.

García-Pérez, J.I. and F. Muñoz-Bullón (2005a). "Are Temporary Help Agencies Changing Mobility Patterns in the Spanish Labor Market?, Spanish Economic Review, vol. 7, no. 1, pp. 43-65.

García-Pérez, J.I. and F. Muñoz-Bullón (2005b). "Temporary Help Agencies and Occupational Mobility", Oxford Bulletin of Economics and Statistics, vol. 67(2), pp. 163-180.

García-Pérez, J.I. and Y. Rebollo (2007). "The use of permanent contracts across Spanish regions: Do regional wage subsidies work?", UPO working paper 07-08.

García-Serrano, C. (2004): "Temporary Employment, Working Conditions and Expected Exists from Firms", Labour, 18(2), 293-316.

Goldsmith, Arthur H., Veum, Jonathan R. and William Darity, Jr., (1996). "The Psychological Impact of Unemployment and Joblessness", Journal of Socio-Economics, Vol. 25, 3, pp. 333-358.

Goldsmith, Arthur H., Veum, Jonathan R. and William Darity, Jr. (1996). "The Impact of Labor Force History on Self-Esteem and its Component Parts. Anxiety, Alienation and Depression”, Journal of Economic Psychology, 17, pp. 183-220. 
Goldsmith, Arthur H., Veum, Jonathan R. and William Darity, Jr. (1997), "The Impact of Psychological and Human Capital on Wages", Economic Inquiry, October, 35(4), pp. 815-29.

Goldsmith, Arthur H., Veum, Jonathan R. and William Darity, Jr. (1997). "Unemployment, Joblessness, Psychological Well-Being and Self-Esteem: Theory and Evidence", Journal of Socio-Economics, 26,2, pp. 133-158.

Gregory, M. and Jukes, R. (2001). "Unemployment and Subsequent Earnings: Estimating Scarring among British Men 1984-94", The Economic Journal, 111, F607F625.

Güell, M. and Petrongolo (2007). "How binding are legal limits? Transitions from temporary to permanent work in Spain”, Labour Economics, 14(2), pp. 153-183.

Hagen, T. (2003). "Do Fixed-Term Contracts Increase the Long-Term Employment Opportunities for the Unemployed?", ZEW Discussion Paper 03-49, Mannheim, Zentrum für Euroäische Wirtschaftsforschung.

Heckman, J.J. and Singer, B. (1984). "A Method for Minimising the Impact of Distributional Assumptions in Econometric Models for Duration Data", Econometrica, 52, pp. 272-320.

Honoré, B.E. (1993). "Identification results for duration models with multiple spells", Review of Economics and Stastistics, 60, 241-246

Houseman, S.N., A.L. Kalleberg and G.A. Erickcek (2003), "The role of temporary help employment in tight labor markets", Upjohn Institute Staff Working Paper 01-73.

Jenkins, S. (1995). "Easy Estimation Methods for Discrete Time Duration Models". Oxford Bulletin of Economics and Statistics,57(1 ), pp. 120-138.

Jimeno, J.F. and Toharia, L. (1993). "The effects of fixed-term employment contracts on wages, theory and evidence from Spain", Investigaciones Económicas, vol. XVII (3), pp. 475-494.

Kugler, A., Jimeno, Juan F., and Herranz, V. (2003). "Employment Consequences of Restrictive Permanent Contracts: Evidence from Spanish Labor Market Reforms", CEPR Discussion Paper No. 3724.

Lancaster, T. (1990). The Econometric Analysis of Transition Data, Cambridge: Cambridge University Press.

Mincer, J. and Offek, H. (1982). "Interrupted Work Careers: Depreciation and Restoriation of Human Capital", Journal of Human Resources, 17, pp. 3-24.

OECD (2002), Taking the measure of temporary employment, in Employment Outlook, Paris.

Segura, J., Durán, F., Toharia, L. and Bentolila, S. (1991). Análisis de la Contratación Temporal en España, Ministerio de Trabajo y Seguridad Social, Madrid.

Storrie, D. (2002), "Temporary agency work in the European Union", Department of Economics, University of Gothenburg: Mimeo.

Toharia, L. (1996), "Empleo y Paro en España: Evolución, Situación y Perspectivas", Economiaz 35, pp. 36-61.

Van den Berg, G.J. (2001). "Duration models: specification, identification and multiple durations", in Heckman, J. and E. Leamer, eds., Handbook of Econometrics, $15,647-665$.

Van Ours, J. C. (2004). "The locking-in effect of subsidized jobs", Journal of Comparative Economics, 32, 37-55.

Zijl, M., Van Den Berg, G. Heyma, A. (2004). "Stepping-stones for the unemployed: the effect of temporary jobs on the duration until regular work", IZA Discussion paper n. 1241. 


\begin{tabular}{lc} 
APPENDIX & \multicolumn{1}{c}{ TABLE A } \\
& Occupation category groups \\
\hline Category & Description:Social Security Contribution Category \\
\hline High & 1- ingenieros and licenciados - engineers and graduates \\
& 2- ingenieros técnicos, peritos and ayudantes titulados - technical \\
& engineers and other skilled workers \\
& 3- jefes administrativos and de taller - chief and departmental heads \\
& 4 - ayudantes no titulados - other semi-skilled workers \\
& 5 - oficiales administrativos - skilled clerks \\
& 6 - subalternos - auxiliary workers \\
& 7 - auxiliares administrativos - semi-skilled clerks \\
Intermediate & 8 - oficiales de primera and segunda - skilled laborers \\
& 9 - oficiales de tercera and especialistas - semi-skilled laborers \\
& 10 - peones - unskilled laborers \\
\hline
\end{tabular}

Table B

Description of Work Contract Denominations Used in the Analysis

\begin{tabular}{ll}
\hline Work Contract Name & Description \\
\hline $\begin{array}{l}\text { Work-Experience } \\
\text { (Practice) Contract }\end{array}$ & $\begin{array}{l}\text { The purpose of this contract is to enable persons who have } \\
\text { completed secondary, vocational training or university education } \\
\text { to gain work experience according to their educational level. }\end{array}$ \\
$\begin{array}{l}\text { (Contrato de prácticas) } \\
\text { Training Contract }\end{array}$ & $\begin{array}{l}\text { This contract is related to the provision of theoretical and } \\
\text { practical knowledge required to perform a skilled job. This } \\
\text { contract replaced the old apprenticeship contract in 1997. }\end{array}$ \\
$\begin{array}{l}\text { Interim Contract } \\
\text { (Contrato de interinidad) }\end{array}$ & $\begin{array}{l}\text { This temporary contract is related to interim situations in the firm } \\
\text { Per-task Contract }\end{array}$ \\
$\begin{array}{l}\text { (Contrato de obra } o \\
\text { servicio) }\end{array}$ & $\begin{array}{l}\text { This contract was introduced for temporary needs of the firms } \\
\text { presumably not permanent). }\end{array}$ \\
$\begin{array}{l}\text { Casual Contract } \\
\text { (Contrato eventual por } \\
\text { circunstancias de la } \\
\text { producción) }\end{array}$ & $\begin{array}{l}\text { This contract is related to unusual or seasonal circumstances of } \\
\text { the goods markets and excess of work in the firm. }\end{array}$ \\
\hline
\end{tabular}


Table 1. TC spells composition

\begin{tabular}{|c|c|c|c|c|}
\hline & n. of spells & $\%$ & Mean length & $\%$ in first spell \\
\hline \multicolumn{5}{|l|}{ HIGH QUAL. } \\
\hline \multicolumn{5}{|l|}{ Type of contract } \\
\hline Work-experience & 1,042 & 7.72 & $12.241(11.103)$ & 17.05 \\
\hline Training & 83 & 0.61 & $10.072(8.531)$ & 0.06 \\
\hline Interim & 2,125 & 15.74 & $3.395(2.544)$ & 9.74 \\
\hline Per task & 3,513 & 26.02 & $6.083(4.279)$ & 21.00 \\
\hline Casual & 4,038 & 29.91 & 3.637 (3.359) & 24.96 \\
\hline Other & 2,698 & 19.99 & $11.709(6.119)$ & 27.18 \\
\hline \multicolumn{5}{|l|}{ Dedication } \\
\hline Part-time & 4,485 & 33.22 & $4.252(3.684)$ & 35.89 \\
\hline Full-time & 9,014 & 66.78 & $5.541(4.329)$ & 64.11 \\
\hline \multicolumn{4}{|l|}{ MEDIUM QUAL. } & Type of contract \\
\hline Work-experience & 905 & 3.62 & $10.940(10.021)$ & 4.87 \\
\hline Training & 289 & 1.16 & $10.806(9.987)$ & 0.02 \\
\hline Interim & 2,006 & 8.03 & $3.152(2.382)$ & 4.37 \\
\hline Per task & 6,744 & 26.99 & $5.068(2.931)$ & 21.22 \\
\hline Casual & 9,931 & 39.74 & $3.576(3.583)$ & 39.19 \\
\hline Other & 5,112 & 20.46 & $11.152(5.649)$ & 30.35 \\
\hline \multicolumn{5}{|l|}{ Dedication } \\
\hline Part-time & 9,322 & 37.31 & $3.827(3.259)$ & 44.86 \\
\hline Full-time & 15,665 & 62.69 & $4.617(3.829)$ & 55.14 \\
\hline \multicolumn{5}{|l|}{$L O W Q U A L$} \\
\hline Work-experience & 980 & 1.81 & 10.947 (9.959) & 1.63 \\
\hline Training & 3,849 & 7.12 & $11.436(10.781)$ & 20.62 \\
\hline Interim & 2,579 & 4.77 & $2.981(2.255)$ & 1.88 \\
\hline Per task & 17,186 & 31.81 & $5.098(3.700)$ & 22.48 \\
\hline Casual & 21,133 & 39.11 & 3.677 (3.394) & 31.29 \\
\hline Other & 8,302 & 15.37 & $11.004(5.727)$ & 22.10 \\
\hline \multicolumn{5}{|l|}{ Dedication } \\
\hline Part-time & 14,151 & 26.19 & $3.770(3.271)$ & 29.02 \\
\hline Full-time & 39,878 & 73.81 & $5.131(4.294)$ & 70.98 \\
\hline
\end{tabular}

Note: sample size is 3366 individuals for the High Qual. group, 5816 for the Medium Qual. group and 11,776 for the Low group. All individuals are between 16 and 25 years-old in 1996 and their first spell is temporary. "Median length" measured in months, in parentheses for complete spells only. 
Table 2. Number of individuals by TC and non-employment experiences (\%)

\begin{tabular}{|c|c|c|c|c|c|c|c|c|c|c|c|c|}
\hline \multirow{3}{*}{$\begin{array}{l}\text { Number } \\
\text { of TC } \\
\text { spells }\end{array}$} & \multicolumn{12}{|c|}{ Number of Unemployment spells } \\
\hline & \multicolumn{12}{|c|}{ HIGH QUAL. } \\
\hline & 0 & 1 & 2 & 3 & 4 & 5 & 6 & 7 & 8 & 9 & $>9$ & Total \\
\hline 1 & $17.3 \%$ & $7.6 \%$ & $1.7 \%$ & $0.0 \%$ & $0.0 \%$ & $0.0 \%$ & $0.0 \%$ & $0.0 \%$ & $0.0 \%$ & $0.0 \%$ & $0.0 \%$ & $26.6 \%$ \\
\hline 2 & $6.8 \%$ & $8.9 \%$ & $4.8 \%$ & $0.7 \%$ & $0.0 \%$ & $0.0 \%$ & $0.0 \%$ & $0.0 \%$ & $0.0 \%$ & $0.0 \%$ & $0.0 \%$ & $21.2 \%$ \\
\hline 3 & $2.1 \%$ & $3.8 \%$ & $5.3 \%$ & $2.3 \%$ & $0.2 \%$ & $0.0 \%$ & $0.0 \%$ & $0.0 \%$ & $0.0 \%$ & $0.0 \%$ & $0.0 \%$ & $13.7 \%$ \\
\hline 4 & $0.7 \%$ & $1.5 \%$ & $3.2 \%$ & $3.4 \%$ & $1.5 \%$ & $0.3 \%$ & $0.0 \%$ & $0.0 \%$ & $0.0 \%$ & $0.0 \%$ & $0.0 \%$ & $10.5 \%$ \\
\hline 5 & $0.3 \%$ & $0.7 \%$ & $1.5 \%$ & $1.8 \%$ & $1.4 \%$ & $0.6 \%$ & $0.0 \%$ & $0.0 \%$ & $0.0 \%$ & $0.0 \%$ & $0.0 \%$ & $6.4 \%$ \\
\hline 6 & $0.1 \%$ & $0.4 \%$ & $0.8 \%$ & $0.8 \%$ & $1.1 \%$ & $1.1 \%$ & $0.5 \%$ & $0.1 \%$ & $0.0 \%$ & $0.0 \%$ & $0.0 \%$ & $4.9 \%$ \\
\hline 7 & $0.1 \%$ & $0.1 \%$ & $0.3 \%$ & $0.5 \%$ & $0.7 \%$ & $0.9 \%$ & $0.9 \%$ & $0.2 \%$ & $0.0 \%$ & $0.0 \%$ & $0.0 \%$ & $3.7 \%$ \\
\hline 8 & $0.0 \%$ & $0.0 \%$ & $0.1 \%$ & $0.4 \%$ & $0.6 \%$ & $0.7 \%$ & $0.9 \%$ & $0.4 \%$ & $0.1 \%$ & $0.0 \%$ & $0.0 \%$ & $3.2 \%$ \\
\hline 9 & $0.0 \%$ & $0.1 \%$ & $0.1 \%$ & $0.1 \%$ & $0.4 \%$ & $0.5 \%$ & $0.3 \%$ & $0.4 \%$ & $0.1 \%$ & $0.1 \%$ & $0.0 \%$ & $1.9 \%$ \\
\hline$>9$ & $0.1 \%$ & $0.1 \%$ & $0.4 \%$ & $0.4 \%$ & $0.9 \%$ & $0.7 \%$ & $0.9 \%$ & $0.9 \%$ & $0.8 \%$ & $0.7 \%$ & $2.1 \%$ & $7.8 \%$ \\
\hline \multirow[t]{3}{*}{ Total } & $27.4 \%$ & $23.2 \%$ & $18.2 \%$ & $10.5 \%$ & $6.7 \%$ & $4.9 \%$ & $3.4 \%$ & $1.9 \%$ & $1.0 \%$ & $0.8 \%$ & $2.1 \%$ & 3366 \\
\hline & \multicolumn{12}{|c|}{ MEDIUM QUAL. } \\
\hline & 0 & 1 & 2 & 3 & 4 & 5 & 6 & 7 & 8 & 9 & $>9$ & Total \\
\hline 1 & $12.0 \%$ & $8.3 \%$ & $1.7 \%$ & $0.0 \%$ & $0.0 \%$ & $0.0 \%$ & $0.0 \%$ & $0.0 \%$ & $0.0 \%$ & $0.0 \%$ & $0.0 \%$ & $22.1 \%$ \\
\hline 2 & $4.1 \%$ & $9.0 \%$ & $5.8 \%$ & $1.0 \%$ & $0.0 \%$ & $0.0 \%$ & $0.0 \%$ & $0.0 \%$ & $0.0 \%$ & $0.0 \%$ & $0.0 \%$ & $19.9 \%$ \\
\hline 3 & $1.7 \%$ & $3.9 \%$ & $5.4 \%$ & $2.8 \%$ & $0.4 \%$ & $0.0 \%$ & $0.0 \%$ & $0.0 \%$ & $0.0 \%$ & $0.0 \%$ & $0.0 \%$ & $14.3 \%$ \\
\hline 4 & $0.7 \%$ & $1.9 \%$ & $3.0 \%$ & $3.4 \%$ & $1.6 \%$ & $0.2 \%$ & $0.0 \%$ & $0.0 \%$ & $0.0 \%$ & $0.0 \%$ & $0.0 \%$ & $10.8 \%$ \\
\hline 5 & $0.3 \%$ & $0.8 \%$ & $1.5 \%$ & $2.3 \%$ & $2.1 \%$ & $1.1 \%$ & $0.2 \%$ & $0.0 \%$ & $0.0 \%$ & $0.0 \%$ & $0.0 \%$ & $8.3 \%$ \\
\hline 6 & $0.1 \%$ & $0.4 \%$ & $0.9 \%$ & $1.7 \%$ & $1.4 \%$ & $1.3 \%$ & $0.7 \%$ & $0.1 \%$ & $0.0 \%$ & $0.0 \%$ & $0.0 \%$ & $6.4 \%$ \\
\hline 7 & $0.0 \%$ & $0.1 \%$ & $0.4 \%$ & $0.8 \%$ & $0.7 \%$ & $1.2 \%$ & $0.8 \%$ & $0.3 \%$ & $0.0 \%$ & $0.0 \%$ & $0.0 \%$ & $4.4 \%$ \\
\hline 8 & $0.0 \%$ & $0.1 \%$ & $0.2 \%$ & $0.4 \%$ & $0.6 \%$ & $0.7 \%$ & $0.6 \%$ & $0.5 \%$ & $0.1 \%$ & $0.0 \%$ & $0.0 \%$ & $3.0 \%$ \\
\hline 9 & $0.0 \%$ & $0.0 \%$ & $0.1 \%$ & $0.3 \%$ & $0.4 \%$ & $0.4 \%$ & $0.6 \%$ & $0.3 \%$ & $0.2 \%$ & $0.1 \%$ & $0.0 \%$ & $2.4 \%$ \\
\hline$>9$ & $0.0 \%$ & $0.1 \%$ & $0.1 \%$ & $0.3 \%$ & $0.5 \%$ & $0.7 \%$ & $0.9 \%$ & $1.0 \%$ & $1.0 \%$ & $0.9 \%$ & $2.7 \%$ & $8.4 \%$ \\
\hline \multirow[t]{3}{*}{ Total } & $19.1 \%$ & $24.7 \%$ & $19.3 \%$ & $12.9 \%$ & $7.6 \%$ & $5.5 \%$ & $3.7 \%$ & $2.2 \%$ & $1.3 \%$ & $1.0 \%$ & $2.7 \%$ & 5816 \\
\hline & \multicolumn{12}{|c|}{ LOW QUAL. } \\
\hline & 0 & 1 & 2 & 3 & 4 & 5 & 6 & 7 & 8 & 9 & $>9$ & Total \\
\hline 1 & $11.8 \%$ & $6.0 \%$ & $1.9 \%$ & $0.0 \%$ & $0.0 \%$ & $0.0 \%$ & $0.0 \%$ & $0.0 \%$ & $0.0 \%$ & $0.0 \%$ & $0.0 \%$ & $19.6 \%$ \\
\hline 2 & $3.6 \%$ & $8.3 \%$ & $5.3 \%$ & $0.9 \%$ & $0.0 \%$ & $0.0 \%$ & $0.0 \%$ & $0.0 \%$ & $0.0 \%$ & $0.0 \%$ & $0.0 \%$ & $18.0 \%$ \\
\hline 3 & $1.3 \%$ & $3.7 \%$ & $6.0 \%$ & $3.2 \%$ & $0.5 \%$ & $0.0 \%$ & $0.0 \%$ & $0.0 \%$ & $0.0 \%$ & $0.0 \%$ & $0.0 \%$ & $14.5 \%$ \\
\hline 4 & $0.5 \%$ & $1.8 \%$ & $3.2 \%$ & $3.7 \%$ & $1.9 \%$ & $0.3 \%$ & $0.0 \%$ & $0.0 \%$ & $0.0 \%$ & $0.0 \%$ & $0.0 \%$ & $11.3 \%$ \\
\hline 5 & $0.2 \%$ & $0.8 \%$ & $1.6 \%$ & $2.4 \%$ & $2.3 \%$ & $1.1 \%$ & $0.1 \%$ & $0.0 \%$ & $0.0 \%$ & $0.0 \%$ & $0.0 \%$ & $8.5 \%$ \\
\hline 6 & $0.1 \%$ & $0.5 \%$ & $0.7 \%$ & $1.5 \%$ & $1.8 \%$ & $1.5 \%$ & $0.6 \%$ & $0.1 \%$ & $0.0 \%$ & $0.0 \%$ & $0.0 \%$ & $6.6 \%$ \\
\hline 7 & $0.1 \%$ & $0.2 \%$ & $0.5 \%$ & $0.7 \%$ & $1.0 \%$ & $1.1 \%$ & $0.9 \%$ & $0.4 \%$ & $0.0 \%$ & $0.0 \%$ & $0.0 \%$ & $4.9 \%$ \\
\hline 8 & $0.0 \%$ & $0.1 \%$ & $0.2 \%$ & $0.5 \%$ & $0.5 \%$ & $0.8 \%$ & $0.7 \%$ & $0.5 \%$ & $0.2 \%$ & $0.0 \%$ & $0.0 \%$ & $3.5 \%$ \\
\hline 9 & $0.0 \%$ & $0.0 \%$ & $0.1 \%$ & $0.2 \%$ & $0.4 \%$ & $0.6 \%$ & $0.5 \%$ & $0.4 \%$ & $0.3 \%$ & $0.1 \%$ & $0.0 \%$ & $2.6 \%$ \\
\hline$>9$ & $0.1 \%$ & $0.1 \%$ & $0.1 \%$ & $0.6 \%$ & $0.8 \%$ & $0.9 \%$ & $1.1 \%$ & $1.4 \%$ & $1.5 \%$ & $1.1 \%$ & $2.8 \%$ & $10.4 \%$ \\
\hline Total & $17.5 \%$ & $21.3 \%$ & $19.6 \%$ & $13.5 \%$ & $9.2 \%$ & $6.3 \%$ & $3.9 \%$ & $2.6 \%$ & $2.0 \%$ & $1.2 \%$ & $2.8 \%$ & 11776 \\
\hline
\end{tabular}

Source: Social Security Records and authors' own elaboration. 
Table 3. Length of spell by type of transition

\begin{tabular}{|c|c|c|c|c|c|c|c|c|c|c|}
\hline \multicolumn{11}{|c|}{ HIGH QUAL. } \\
\hline \multirow[t]{2}{*}{ Months: } & \multicolumn{2}{|c|}{$T C-T C$} & \multicolumn{2}{|c|}{$T C-P C$} & \multicolumn{2}{|c|}{ TC-Unemp. } & \multicolumn{2}{|c|}{ Unemp.-TC } & \multicolumn{2}{|c|}{ Unemp.-PC } \\
\hline & $n$. & $\%$ & $n$. & $\%$ & $n$ & $\%$ & $n$. & $\%$ & $n$ & $\%$ \\
\hline $0-6$ & 543 & 69.35 & 122 & 37.54 & 1589 & 84.07 & 967 & 63.37 & 122 & 59.22 \\
\hline $7-12$ & 131 & 16.73 & 81 & 24.92 & 227 & 12.01 & 335 & 21.95 & 36 & 17.48 \\
\hline $13-18$ & 47 & 6.00 & 37 & 11.38 & 36 & 1.90 & 123 & 8.06 & 25 & 12.14 \\
\hline $19-24$ & 42 & 5.36 & 62 & 19.08 & 30 & 1.59 & 64 & 4.19 & 10 & 4.85 \\
\hline $25-30$ & 11 & 1.40 & 9 & 3.69 & 4 & 0.21 & 37 & 2.42 & 13 & 6.31 \\
\hline $31-36$ & 6 & 0.77 & 2 & 2.77 & 2 & 0.11 & - & - & - & - \\
\hline$>36$ & 3 & 0.38 & - & 0.62 & 2 & 0.11 & - & - & - & - \\
\hline Total: & 783 & & 325 & & 1890 & & 1526 & & 206 & \\
\hline Censored: & \multicolumn{6}{|c|}{368} & \multicolumn{4}{|c|}{158} \\
\hline \multicolumn{11}{|c|}{ MEDIUM QUAL. } \\
\hline \multirow[t]{2}{*}{ Months: } & \multicolumn{2}{|c|}{$T C-T C$} & \multicolumn{2}{|c|}{$T C-P C$} & \multicolumn{2}{|c|}{ TC-Unemp. } & \multicolumn{2}{|c|}{ Unетр.-TC } & \multicolumn{2}{|c|}{ Unemp.-PC } \\
\hline & $n$ & $\%$ & $n$ & $\%$ & $n$ & $\%$ & $n$ & $\%$ & $n$ & $\%$ \\
\hline $0-6$ & 964 & 79.74 & 234 & 51.54 & 3386 & 88.62 & 1886 & 61.29 & 251 & 61.37 \\
\hline $7-12$ & 154 & 12.74 & 115 & 25.33 & 292 & 7.64 & 746 & 24.24 & 69 & 16.87 \\
\hline $13-18$ & 42 & 3.47 & 49 & 10.79 & 71 & 1.86 & 220 & 7.15 & 54 & 13.20 \\
\hline $19-24$ & 35 & 2.89 & 32 & 7.05 & 47 & 1.23 & 155 & 5.04 & 18 & 4.40 \\
\hline $25-30$ & 5 & 0.41 & 11 & 2.42 & 11 & 0.29 & 70 & 2.27 & 17 & 4.16 \\
\hline $31-36$ & 6 & 0.50 & 11 & 2.42 & 8 & 0.21 & -- & -- & -- & -- \\
\hline$>36$ & 3 & 0.25 & 2 & 0.44 & 6 & 0.16 & -- & -- & -- & -- \\
\hline Total: & 1209 & & 454 & & 3821 & & 3077 & & 409 & \\
\hline Censored: & & & & 332 & & & & & 35 & \\
\hline \multicolumn{11}{|c|}{ LOW QUAL. } \\
\hline \multirow[t]{2}{*}{ Months: } & \multicolumn{2}{|c|}{$T C-T C$} & \multicolumn{2}{|c|}{$T C-P C$} & \multicolumn{2}{|c|}{ TC-Unemp. } & \multicolumn{2}{|c|}{ Unemp.-TC } & \multicolumn{2}{|c|}{ Unemp.-PC } \\
\hline & $n$. & $\%$ & $n$. & $\%$ & $n$. & $\%$ & $n$. & $\%$ & $n$ & $\%$ \\
\hline $0-6$ & 1766 & 71.32 & 289 & 37.88 & 6635 & 85.29 & 3,737 & 57.57 & 371 & 57.88 \\
\hline $7-12$ & 336 & 13.57 & 159 & 20.84 & 642 & 8.25 & 1,646 & 25.36 & 125 & 19.50 \\
\hline $13-18$ & 141 & 5.69 & 69 & 9.04 & 294 & 3.78 & 541 & 8.33 & 61 & 9.52 \\
\hline $19-24$ & 159 & 6.42 & 180 & 23.59 & 147 & 1.89 & 373 & 5.75 & 54 & 8.42 \\
\hline $25-30$ & 30 & 1.21 & 12 & 1.57 & 25 & 0.32 & 194 & 2.99 & 30 & 4.68 \\
\hline $31-36$ & 38 & 1.53 & 51 & 6.68 & 33 & 0.42 & -- & -- & - & - \\
\hline$>36$ & 6 & 0.24 & 3 & 0.39 & 3 & 0.04 & -- & -- & -- & - \\
\hline Total: & 2476 & & 763 & & 7779 & & 6,491 & & 641 & \\
\hline Censored: & \multicolumn{6}{|c|}{758} & \multicolumn{4}{|c|}{647} \\
\hline
\end{tabular}

Source: Social Security Records and authors' own elaboration. 
Table 4. Main descriptive statistics for the first TC spell

\begin{tabular}{|c|c|c|c|}
\hline \multirow[t]{2}{*}{ Variable } & High Qual. & Medium Qual. & Low Qual. \\
\hline & Mean (S.D.) & Mean (S.D.) & Mean (S.D.) \\
\hline Age & $21.978 \quad(2.406)$ & (2.427) & 19.466 \\
\hline Equal Employer & 0.342 & 0.334 & 0.247 \\
\hline Gender (=1 if male) & 0.399 & 0.330 & 0.603 \\
\hline Temporary Help Agency & 0.235 & 0.174 & 0.209 \\
\hline Qualification & & & \\
\hline Upper-High Qual. & 0.376 & 0.000 & 0.000 \\
\hline Lower-High Qual & 0.624 & 0.000 & 0.000 \\
\hline Medium Qual. & 0.000 & 1.000 & 0.000 \\
\hline Low Qual. & 0.000 & 0.000 & 1.000 \\
\hline Type of contract & & & \\
\hline Work-exper. Contract & 0.171 & 0.049 & 0.016 \\
\hline Training contract & 0.001 & 0.000 & 0.206 \\
\hline Interim contract & 0.097 & 0.044 & 0.019 \\
\hline Per task contract & 0.210 & 0.212 & 0.225 \\
\hline Casual contract & 0.250 & 0.392 & 0.313 \\
\hline Other contract & 0.272 & 0.303 & 0.221 \\
\hline Part-time & 0.359 & 0.449 & 0.290 \\
\hline Number of observations & 3366 & 5816 & 11766 \\
\hline
\end{tabular}

Note: Upper-High qualification collects social security contribution groups 1, 2 and 3; Lower-High qualification collects social security contribution groups 4, 5 and 6 (see Appendix A). 
Figure 1.1. Transitions from the first TC. High Qualification

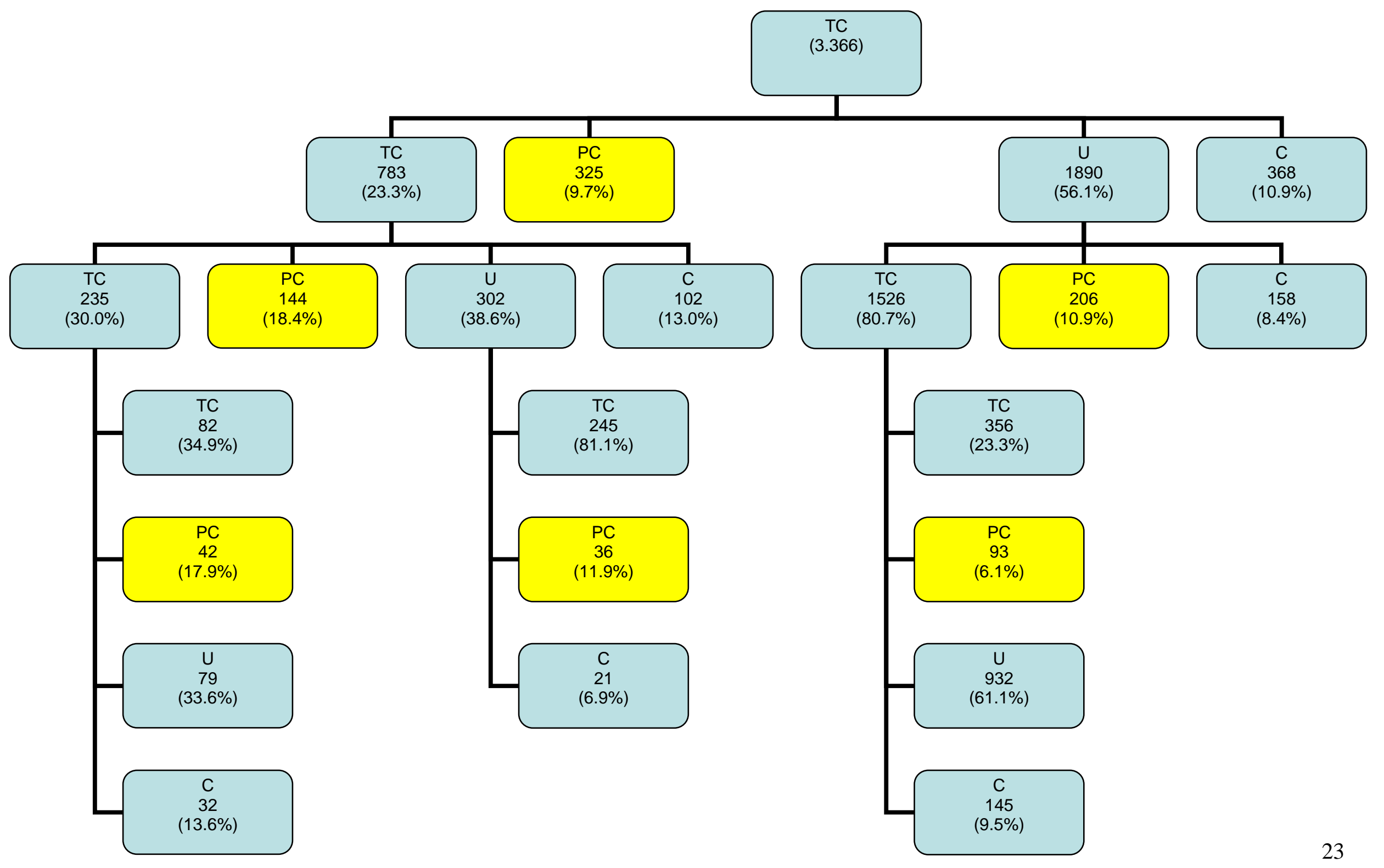


Figure 1.2. Transitions from the first TC. Medium Qualification

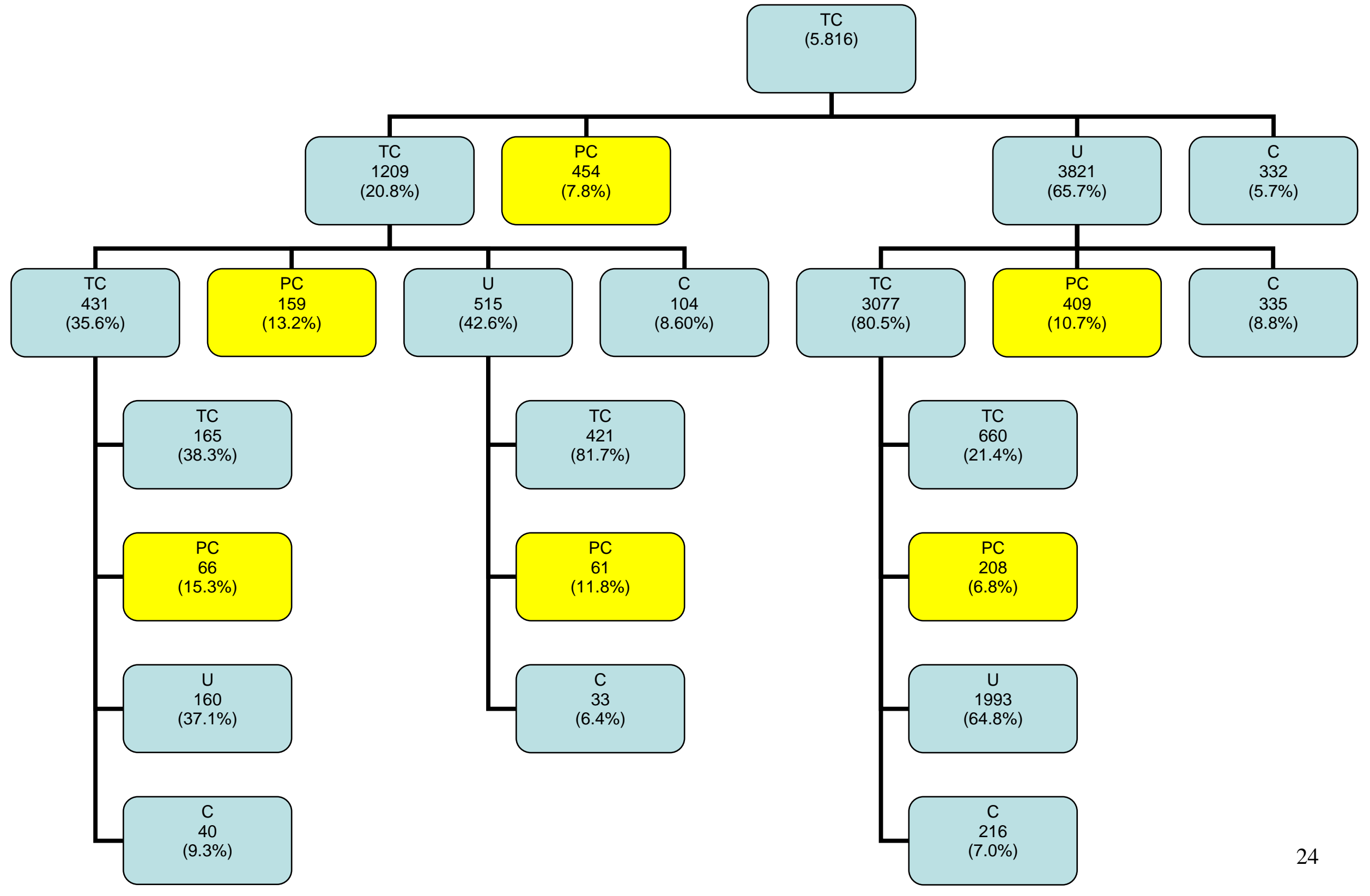


Figure 1.3. Transitions from the first TC. Low Qualification

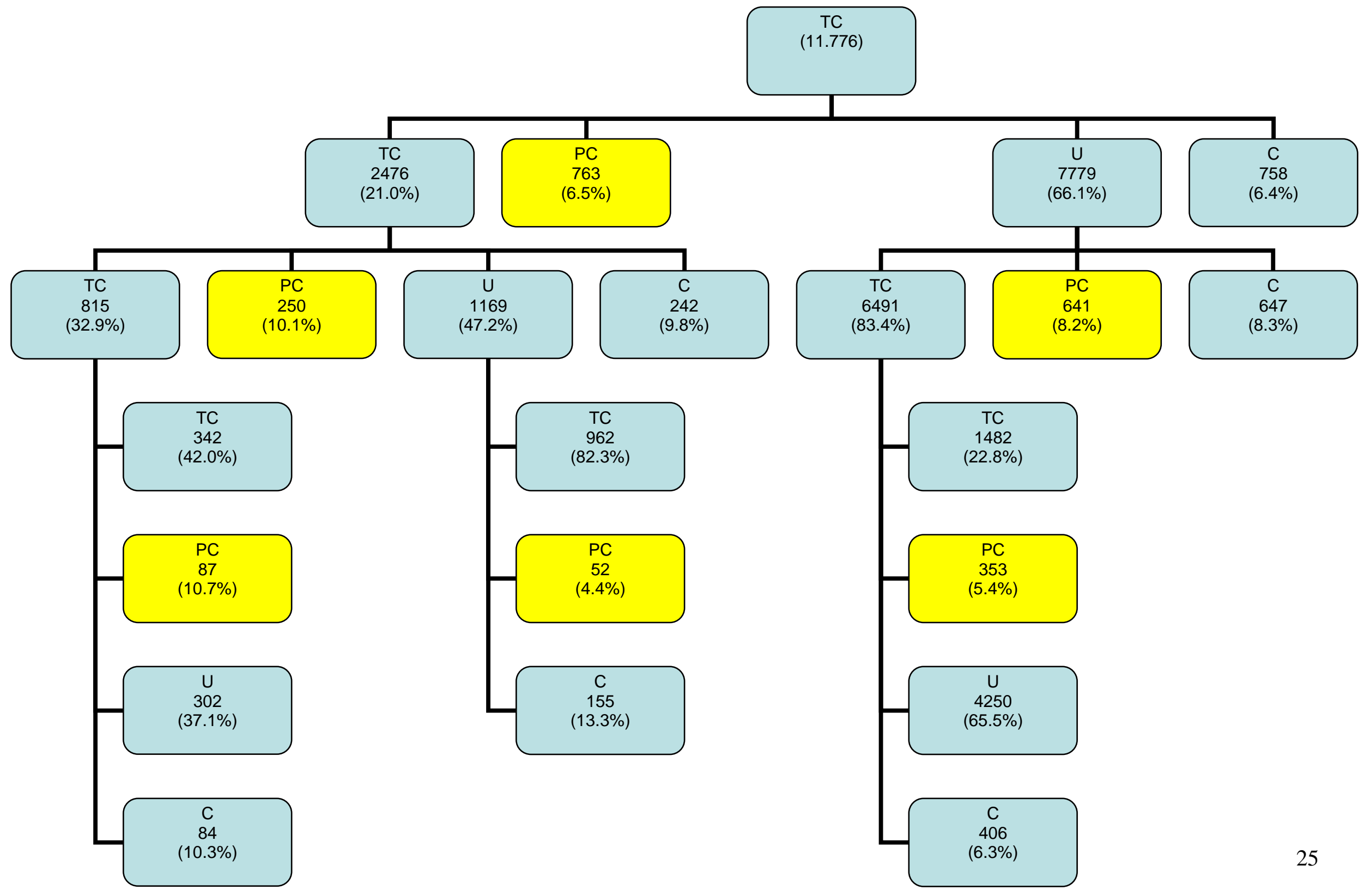


Table 6. Regression estimates. High Qualification group

\begin{tabular}{|c|c|c|c|c|c|c|c|c|c|c|}
\hline & \multicolumn{2}{|c|}{ TC-Unemployment } & \multicolumn{2}{|c|}{$T C-T C$} & \multicolumn{2}{|c|}{$T C-P C$} & \multicolumn{2}{|c|}{ Unempl-TC } & \multicolumn{2}{|c|}{ Unempl-PC } \\
\hline & Coef. & t-statistic & Coef. & t-statistic & Coef. & t-statistic & Coef. & t-statistic & Coef. & t-statistic \\
\hline $\log (t)$ & -1.223 & -26.51 & -1.582 & -27.85 & -0.657 & -5.88 & -0.487 & -8.82 & -0.685 & -4.89 \\
\hline $\log (t) 2$ & 0.197 & 11.14 & 0.347 & 16.78 & 0.234 & 6.94 & 0.058 & 2.79 & 0.170 & 3.62 \\
\hline No. Previous contracts & -0.015 & -3.72 & 0.048 & 14.74 & -0.002 & -0.15 & 0.079 & 7.31 & -0.092 & -3.28 \\
\hline Previous Unemp. Dur. & 0.019 & 6.21 & -0.017 & -3.58 & -0.010 & -1.17 & -0.018 & -4.13 & -0.023 & -2.13 \\
\hline Previous Emp. Dur. & -0.037 & -9.24 & -0.020 & -4.38 & 0.016 & 2.71 & 0.025 & 4.74 & 0.050 & 4.75 \\
\hline Unemploym. Benefits & - & - & - & - & - & - & -1.170 & -12.56 & -1.176 & -4.94 \\
\hline Unemp. Benefits*Log $(t)$ & - & - & - & - & - & - & 0.358 & 4.16 & 0.545 & 2.77 \\
\hline Age & -0.176 & -2.39 & 0.185 & 2.04 & 0.603 & 3.14 & 0.119 & 1.4 & 0.556 & 2.39 \\
\hline Age2 & 0.001 & 0.82 & -0.006 & -3 & -0.012 & -3.02 & -0.002 & -1.04 & -0.010 & -1.94 \\
\hline Unemp. Rate & 0.000 & 0.1 & -0.004 & -1.11 & -0.057 & -7.82 & -0.021 & -4.61 & -0.057 & -5.53 \\
\hline$\Delta$ Empl. Rate & -0.903 & -1.15 & -0.589 & -0.61 & 2.057 & 1.24 & -0.080 & -0.09 & 4.520 & 2.01 \\
\hline Equal employer & -0.055 & -1.72 & 0.293 & 7.83 & 0.997 & 14.93 & 0.916 & 22.81 & 0.230 & 2.04 \\
\hline Sex & -0.146 & -3.93 & -0.143 & -3.24 & 0.090 & 1.36 & -0.099 & -2.4 & 0.046 & 0.5 \\
\hline THA & 0.365 & 9.46 & 0.477 & 10.72 & -0.450 & -4.56 & 0.095 & 2.32 & -0.387 & -3.38 \\
\hline High Qual. & - & - & - & - & - & - & - & - & - & - \\
\hline Med-High Qual. & 0.433 & 10.17 & 0.135 & 2.63 & 0.275 & 3.26 & -0.122 & -2.49 & -0.122 & -1.04 \\
\hline Med.-Low Qual. & 0.361 & 6.78 & 0.399 & 6.66 & 0.675 & 6.57 & 0.134 & 2.14 & 0.283 & 1.88 \\
\hline Low Qual. & 0.513 & 8.6 & 0.591 & 8.62 & 0.465 & 3.51 & 0.233 & 3.38 & 0.257 & 1.5 \\
\hline Period 6 & 1.006 & 17.14 & 1.105 & 14.71 & 1.267 & 12.4 & - & - & - & - \\
\hline Period 12 & 1.467 & 15.3 & 1.631 & 15.22 & 1.636 & 13.55 & - & - & - & - \\
\hline Period 24 & 1.599 & 8.37 & 2.004 & 11.5 & 2.165 & 12.41 & - & - & - & - \\
\hline Period 36 & 1.054 & 2.9 & 0.820 & 2.01 & 1.044 & 2.37 & - & - & - & - \\
\hline Years 1997-2000 & -0.088 & -1.02 & 0.361 & 2.74 & 1.590 & 2.72 & 0.544 & 4.16 & 0.907 & 1.53 \\
\hline years 2001-2003 & -0.292 & -3.1 & 0.066 & 0.47 & 1.155 & 1.96 & 0.702 & 5.06 & 1.395 & 2.33 \\
\hline Work-exper. Contract & -1.198 & -14.63 & -0.673 & -7.75 & 0.290 & 2.03 & 0.046 & 0.43 & 0.847 & 4.12 \\
\hline Training contract & -1.211 & -6.15 & -1.284 & -4.89 & 0.228 & 0.63 & 0.445 & 1.89 & -0.058 & -0.08 \\
\hline Casual contract & 0.369 & 6.73 & 0.202 & 3.04 & 0.639 & 4.69 & 0.139 & 2.16 & 0.269 & 1.67 \\
\hline Per task contract & 0.150 & 2.8 & -0.227 & -3.47 & -0.158 & -1.15 & 0.119 & 1.85 & 0.010 & 0.06 \\
\hline Interim contract & 0.528 & 8.24 & 0.366 & 5.04 & 0.065 & 0.36 & 0.262 & 3.45 & 0.008 & 0.04 \\
\hline Other & - & - & - & - & - & - & - & - & - & - \\
\hline Part-Time & 0.192 & 4.51 & 0.115 & 2.24 & -0.114 & -1.06 & -0.018 & -0.34 & 0.068 & 0.53 \\
\hline Constant & 2.229 & 2.63 & -3.190 & -3 & -12.667 & -5.48 & -3.567 & -3.68 & -11.457 & -4.24 \\
\hline Prob. Type I & 0.618 & 35.392 & & & & & 0.764 & 24.983 & & \\
\hline Cons. Type I & -0.462 & -4.003 & & & & & -0.222 & -6.558 & & \\
\hline Prob. Type II & 0.382 & - & & & & & 0.236 & - & & \\
\hline Cons. Type II & 0.747 & - & & & & & 0.719 & - & & \\
\hline$\theta_{2} / \gamma_{2}$ & & & & & 0.159 & 0.9 & & & 1.129 & 3.34 \\
\hline No. Observations & 97038 & & & & & & & & & \\
\hline Log Likelihood & -51879.13 & & & & & & & & & \\
\hline
\end{tabular}


Table 7. Regression estimates. Medium Qualification group

\begin{tabular}{|c|c|c|c|c|c|c|c|c|c|c|}
\hline & \multicolumn{2}{|c|}{ TC-Unemployment } & \multicolumn{2}{|c|}{$T C-T C$} & \multicolumn{2}{|c|}{$T C-P C$} & \multicolumn{2}{|c|}{ Unempl-TC } & \multicolumn{2}{|c|}{ Unempl-PC } \\
\hline & Coef. & t-statistic & Coef. & t-statistic & Coef. & t-statistic & Coef. & t-statistic & Coef. & t-statistic \\
\hline $\log (t)$ & -1.441 & -42.44 & -1.502 & -34.58 & -0.413 & -4.86 & -0.643 & -17.8 & -0.712 & -7.76 \\
\hline $\log (t) 2$ & 0.241 & 18.13 & 0.310 & 18.94 & 0.168 & 6.36 & 0.105 & 8.09 & 0.121 & 3.91 \\
\hline No. Previous contracts & -0.010 & -3.37 & 0.033 & 12 & -0.004 & -0.46 & 0.070 & 10.91 & -0.015 & -1.03 \\
\hline Previous Unemp. Dur. & 0.024 & 11.45 & -0.008 & -2.38 & -0.009 & -1.52 & -0.010 & -4 & -0.017 & -2.73 \\
\hline Previous Emp. Dur. & -0.049 & -14.77 & -0.017 & -4.62 & 0.004 & 0.84 & 0.024 & 5.85 & 0.056 & 7.99 \\
\hline Unemploym. Benefits & - & - & - & - & - & - & -1.356 & -19.25 & -0.925 & -5.98 \\
\hline Unemp. Benefits*Log(t) & - & - & - & - & - & - & 0.403 & 6.37 & 0.153 & 1.08 \\
\hline Age & -0.003 & -0.05 & 0.417 & 5.63 & 0.657 & 4.82 & -0.016 & -0.26 & 0.488 & 3.17 \\
\hline Age2 & -0.002 & -1.57 & -0.010 & -6.22 & -0.014 & -4.59 & 0.001 & 0.94 & -0.009 & -2.56 \\
\hline Unemp. Rate & -0.003 & -1.14 & -0.006 & -2.16 & -0.043 & -8.29 & -0.011 & -4.14 & -0.051 & -7.71 \\
\hline$\Delta$ Empl. Rate & 1.313 & 2.36 & 0.787 & 1.1 & 6.258 & 4.97 & -0.063 & -0.1 & 4.253 & 2.88 \\
\hline Equal employer & -0.094 & -4.15 & 0.251 & 9.03 & 0.923 & 18.55 & 0.979 & 34.76 & 0.214 & 2.84 \\
\hline Sex & -0.109 & -4.16 & -0.179 & -5.43 & -0.138 & -2.63 & -0.088 & -2.98 & 0.097 & 1.58 \\
\hline THA & 0.548 & 19.31 & 0.730 & 21.63 & 0.127 & 1.7 & 0.147 & 4.77 & -0.357 & -4.25 \\
\hline High Qual. & -0.648 & -9.45 & -0.446 & -6.03 & -0.248 & -2.1 & 0.182 & 2.16 & -0.131 & -0.67 \\
\hline Med-High Qual. & -0.206 & -5.01 & -0.034 & -0.72 & -0.057 & -0.73 & 0.165 & 3.38 & 0.129 & 1.19 \\
\hline Med.-Low Qual. & - & - & - & - & - & - & - & - & - & - \\
\hline Low Qual. & 0.073 & 2.33 & 0.219 & 5.72 & -0.028 & -0.38 & 0.200 & 5.68 & 0.065 & 0.77 \\
\hline Period 6 & 1.194 & 27.54 & 1.391 & 26.3 & 1.427 & 19.73 & - & - & - & - \\
\hline Period 12 & 1.621 & 22.78 & 1.644 & 19.4 & 1.699 & 18.02 & - & - & - & - \\
\hline Period 24 & 1.818 & 12.28 & 1.547 & 8.55 & 1.973 & 11.84 & - & - & - & - \\
\hline Period 36 & 0.070 & 0.15 & 0.038 & 0.07 & 1.169 & 3.19 & - & - & - & - \\
\hline Years 1997-2000 & -0.094 & -1.51 & 0.488 & 4.56 & 0.856 & 2.65 & 0.595 & 6.25 & 1.682 & 2.88 \\
\hline years 2001-2003 & -0.166 & -2.45 & 0.338 & 3.04 & 0.650 & 1.99 & 0.747 & 7.45 & 2.202 & 3.76 \\
\hline Work-exper. Contract & -1.318 & -17.37 & -0.760 & -9.19 & -0.100 & -0.81 & 0.283 & 2.93 & 0.881 & 5.12 \\
\hline Training contract & -1.433 & -12.94 & -1.383 & -9.29 & 0.144 & 0.72 & 0.318 & 2.46 & 0.369 & 1.21 \\
\hline Casual contract & 0.115 & 2.78 & 0.006 & 0.11 & 0.486 & 4.89 & 0.091 & 1.95 & 0.188 & 1.69 \\
\hline Per task contract & -0.075 & -1.76 & -0.293 & -5.38 & -0.412 & -3.83 & 0.109 & 2.25 & -0.064 & -0.53 \\
\hline Interim contract & 0.143 & 2.46 & 0.186 & 2.7 & 0.384 & 2.89 & 0.310 & 4.69 & 0.157 & 0.94 \\
\hline Other & - & - & - & - & - & - & - & - & - & - \\
\hline Part-Time & 0.099 & 3.12 & -0.010 & -0.25 & -0.118 & -1.51 & 0.013 & 0.36 & -0.131 & -1.57 \\
\hline Constant & 0.823 & 1.3 & -5.833 & -7.02 & -12.329 & -7.82 & -2.445 & -3.5 & -11.087 & -6.13 \\
\hline Prob. Type I & 0.672 & 17.251 & & & & & 0.860 & 63.856 & & \\
\hline Cons. Type I & -0.458 & -8.081 & & & & & -0.141 & -9.452 & & \\
\hline Prob. Type II & 0.328 & - & & & & & 0.140 & - & & \\
\hline Cons. Type II & 0.940 & - & & & & & 0.863 & - & & \\
\hline$\theta_{2} / \gamma_{2}$ & & & & & 0.380 & 3.17 & & & 0.367 & 1.84 \\
\hline No. Observations & 170276 & & & & & & & & & \\
\hline Log Likelihood & -97530.145 & & & & & & & & & \\
\hline
\end{tabular}


Table 8. Regression estimates. Low Qualification group

\begin{tabular}{|c|c|c|c|c|c|c|c|c|c|c|}
\hline & \multicolumn{2}{|c|}{ TC-Unemployment } & \multicolumn{2}{|c|}{$T C-T C$} & \multicolumn{2}{|c|}{$T C-P C$} & \multicolumn{2}{|c|}{ Unempl-TC } & \multicolumn{2}{|c|}{ Unempl-PC } \\
\hline & Coef. & t-statistic & Coef. & t-statistic & Coef. & t-statistic & Coef. & t-statistic & Coef. & t-statistic \\
\hline $\log (t)$ & -1.284 & -57.17 & -1.462 & -50.45 & -0.483 & -7.47 & -0.768 & -31.69 & -0.816 & -12.5 \\
\hline $\log (t) 2$ & 0.224 & 25.94 & 0.334 & 31.55 & 0.209 & 10.46 & 0.164 & 18.6 & 0.171 & 7.65 \\
\hline No. Previous contracts & -0.004 & -1.76 & 0.043 & 17.37 & 0.021 & 3.79 & 0.065 & 12.04 & -0.007 & -0.67 \\
\hline Previous Unemp. Dur. & 0.018 & 13.53 & -0.017 & -8.08 & -0.006 & -1.61 & -0.007 & -4.45 & -0.010 & -2.47 \\
\hline Previous Emp. Dur. & -0.047 & -25.2 & -0.020 & -9.57 & 0.004 & 1.17 & 0.026 & 11.28 & 0.050 & 11.7 \\
\hline Unemploym. Benefits & - & - & - & - & - & - & -1.363 & -30.48 & -1.421 & -11.45 \\
\hline Unemp. Benefits*Log $(t)$ & - & - & - & - & - & - & 0.336 & 8.21 & 0.567 & 5.61 \\
\hline Age & 0.025 & 0.72 & 0.280 & 6.09 & 0.275 & 3.21 & 0.144 & 3.29 & 0.355 & 3.37 \\
\hline Age2 & -0.002 & -2.71 & -0.008 & -7.12 & -0.006 & -3.16 & -0.002 & -2.38 & -0.006 & -2.44 \\
\hline Unemp. Rate & -0.002 & -1.17 & -0.008 & -4.32 & -0.062 & -15.3 & -0.017 & -9.2 & -0.070 & -14.27 \\
\hline$\Delta$ Empl. Rate & -0.035 & -0.09 & 2.051 & 4.22 & 1.897 & 1.96 & 0.547 & 1.32 & 1.485 & 1.38 \\
\hline Equal employer & -0.148 & -9.24 & 0.143 & 7.26 & 0.989 & 25.11 & 0.926 & 46.83 & 0.387 & 7.1 \\
\hline Sex & -0.156 & -9 & 0.050 & 2.33 & -0.067 & -1.77 & 0.113 & 5.55 & 0.045 & 1.04 \\
\hline THA & 0.834 & 44.4 & 1.206 & 55.02 & 0.152 & 2.51 & 0.134 & 6.76 & -0.419 & -7.19 \\
\hline High Qual. & -0.612 & -9.37 & -0.381 & -5.28 & -0.018 & -0.13 & 0.116 & 1.45 & 0.044 & 0.24 \\
\hline Med-High Qual. & -0.260 & -7.84 & -0.328 & -7.95 & 0.237 & 3.32 & 0.117 & 2.98 & -0.007 & -0.07 \\
\hline Med.-Low Qual. & -0.161 & -7.73 & -0.021 & -0.85 & 0.298 & 6.25 & 0.112 & 4.53 & 0.173 & 2.99 \\
\hline Low Qual. & - & - & - & - & - & - & - & - & - & - \\
\hline Period 6 & 1.224 & 44.84 & 1.316 & 36.66 & 1.411 & 25.55 & - & - & - & - \\
\hline Period 12 & 1.529 & 34.36 & 1.705 & 32.58 & 1.612 & 22.5 & - & - & - & - \\
\hline Period 24 & 1.888 & 20.25 & 2.235 & 23.85 & 3.031 & 33.16 & - & - & - & - \\
\hline Period 36 & 1.609 & 8.79 & 1.584 & 8.35 & 2.507 & 14.15 & - & - & - & - \\
\hline Years 1997-2000 & -0.186 & -4.35 & 0.396 & 5.45 & 0.486 & 2.17 & 0.548 & 8.21 & 0.852 & 2.89 \\
\hline years 2001-2003 & -0.393 & -8.54 & 0.219 & 2.89 & 0.229 & 1.01 & 0.815 & 11.65 & 1.356 & 4.57 \\
\hline Work-exper. Contract & -1.093 & -16.54 & -0.866 & -11.6 & -0.508 & -4.34 & 0.349 & 4.13 & 0.531 & 3.01 \\
\hline Training contract & -1.262 & -31.27 & -1.334 & -24.89 & -0.001 & -0.01 & 0.093 & 1.97 & 0.393 & 3.47 \\
\hline Casual contract & 0.257 & 8.43 & 0.027 & 0.69 & 0.431 & 5.46 & 0.132 & 3.73 & 0.145 & 1.71 \\
\hline Per task contract & 0.101 & 3.2 & -0.315 & -7.89 & -0.825 & -9.42 & 0.210 & 5.78 & -0.141 & -1.55 \\
\hline Interim contract & 0.302 & 6.45 & 0.324 & 6.04 & 0.293 & 2.55 & 0.207 & 3.84 & -0.049 & -0.35 \\
\hline Other & - & - & - & - & - & - & - & - & - & - \\
\hline Part-Time & 0.164 & 6.82 & 0.158 & 5.14 & 0.077 & 1.21 & -0.071 & -2.47 & -0.044 & -0.67 \\
\hline Constant & 0.165 & 0.43 & -4.420 & -8.79 & -7.348 & -7.63 & -4.103 & -8.62 & -8.513 & -7.22 \\
\hline Prob. Type I & 0.582 & 25.568 & & & & & 0.794 & 52.755 & & \\
\hline Cons. Type I & -0.451 & -16.697 & & & & & -0.221 & -12.994 & & \\
\hline Prob. Type II & 0.418 & - & & & & & 0.206 & - & & \\
\hline Cons. Type II & 0.626 & - & & & & & 0.851 & - & & \\
\hline$\theta_{2} / \gamma_{2}$ & & & & & 0.223 & 2.15 & & & 0.438 & 3.83 \\
\hline No. Observations & 397867 & & & & & & & & & \\
\hline Log Likelihood & -215498.1 & & & & & & & & & \\
\hline
\end{tabular}


Figure 2.1.Empirical hazard rate from TC. Kaplan Meier estimates. High Qualification group

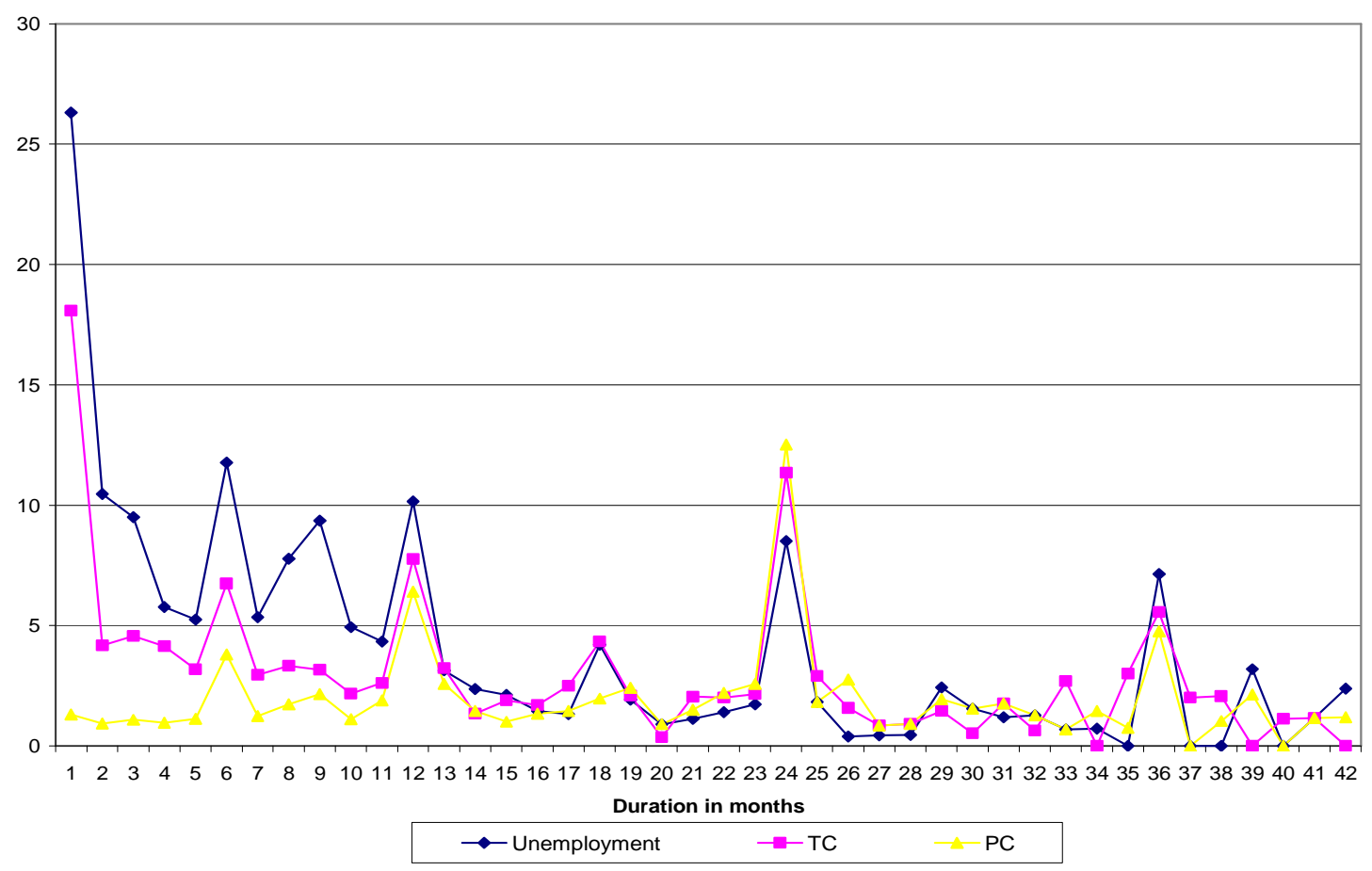

Figure 2.2. Empirical hazard rate from Unemployment. Kaplan Meier estimates. High Qualification Group

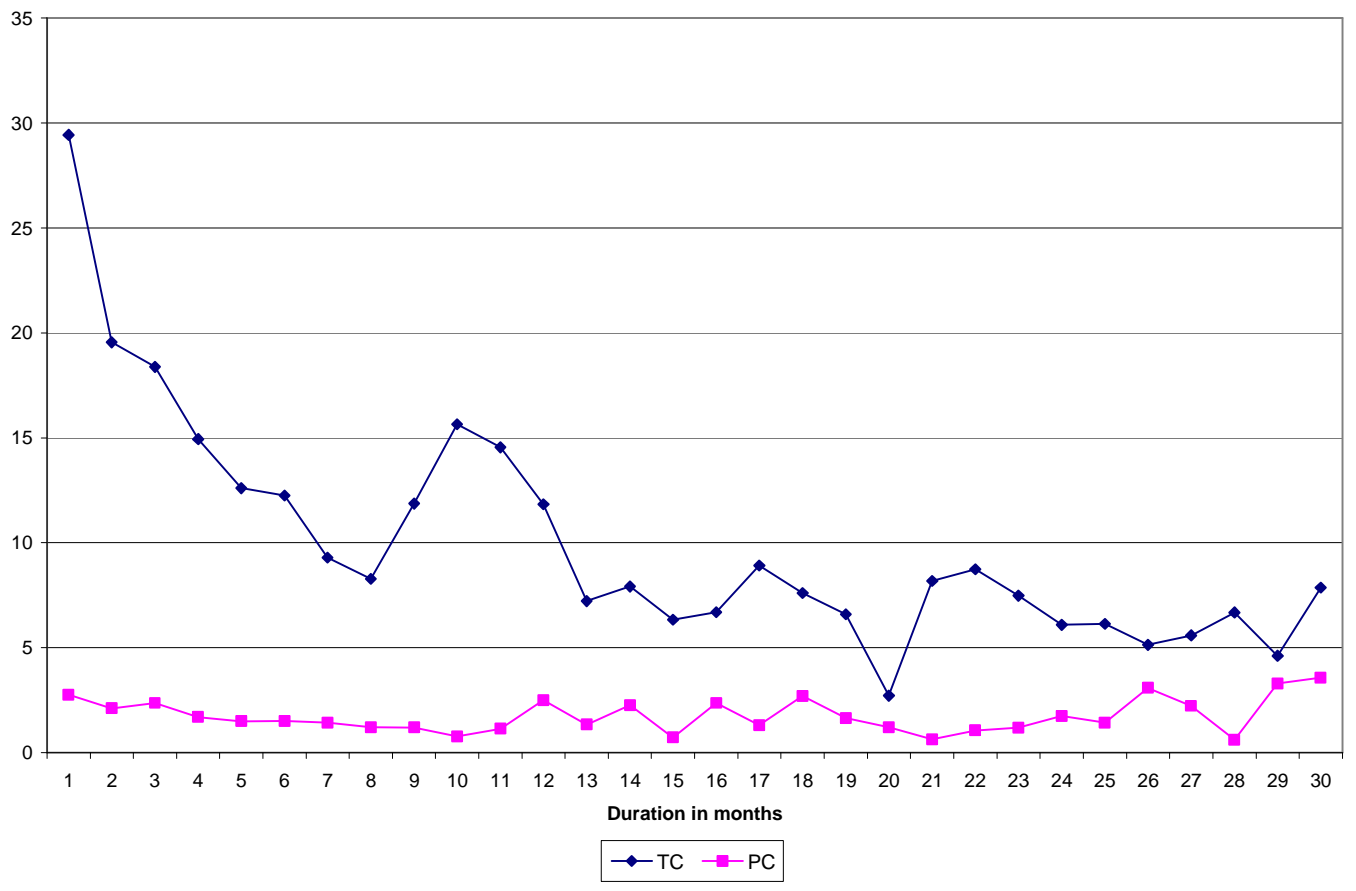


Figure 3.1.Empirical hazard rate from TC. Kaplan Meier estimates. Medium Qualification group

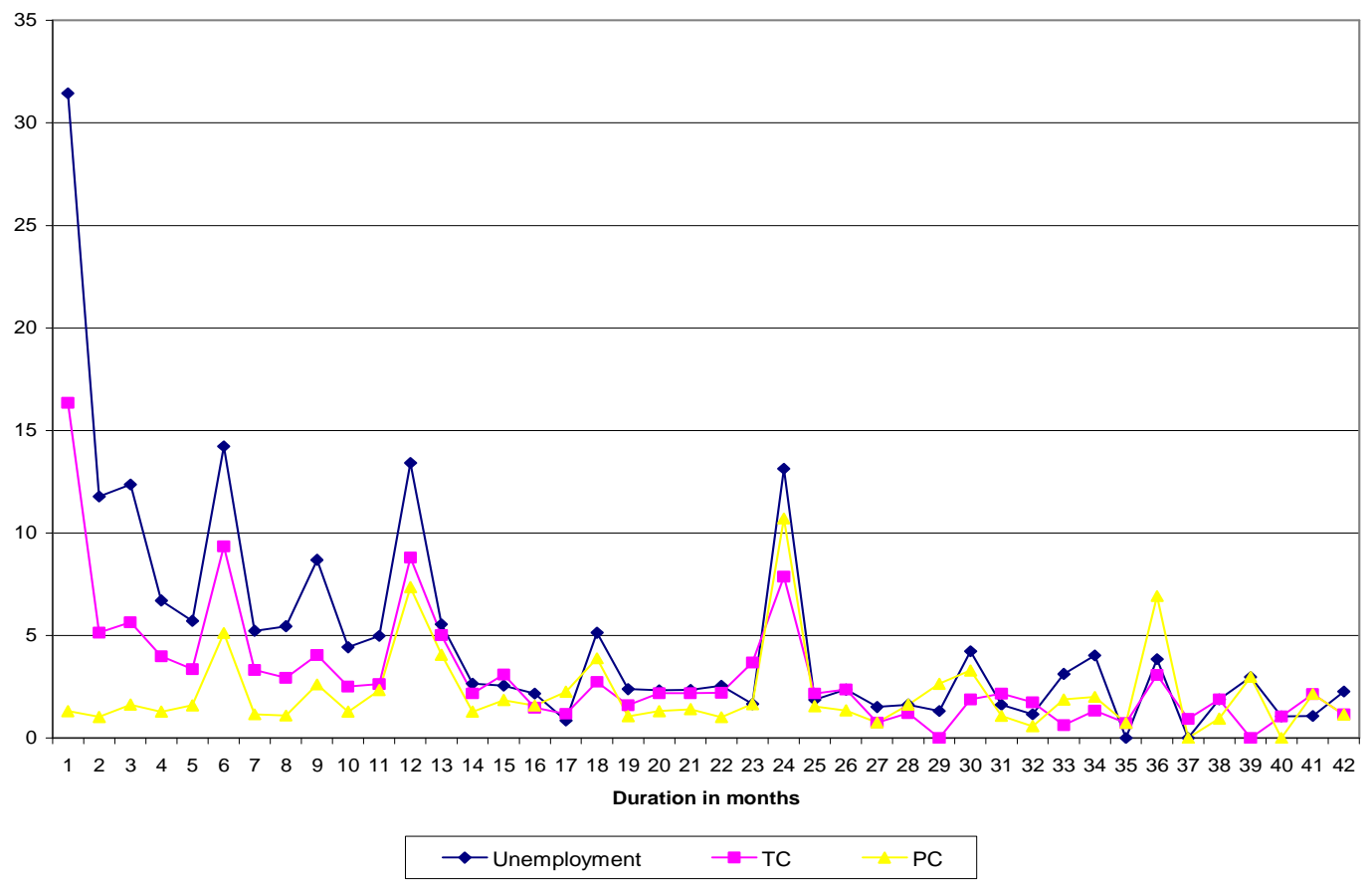

Figure 3.2. Empirical hazard rate from Unemployment. Kaplan Meier estimates. Medium Qualification Group

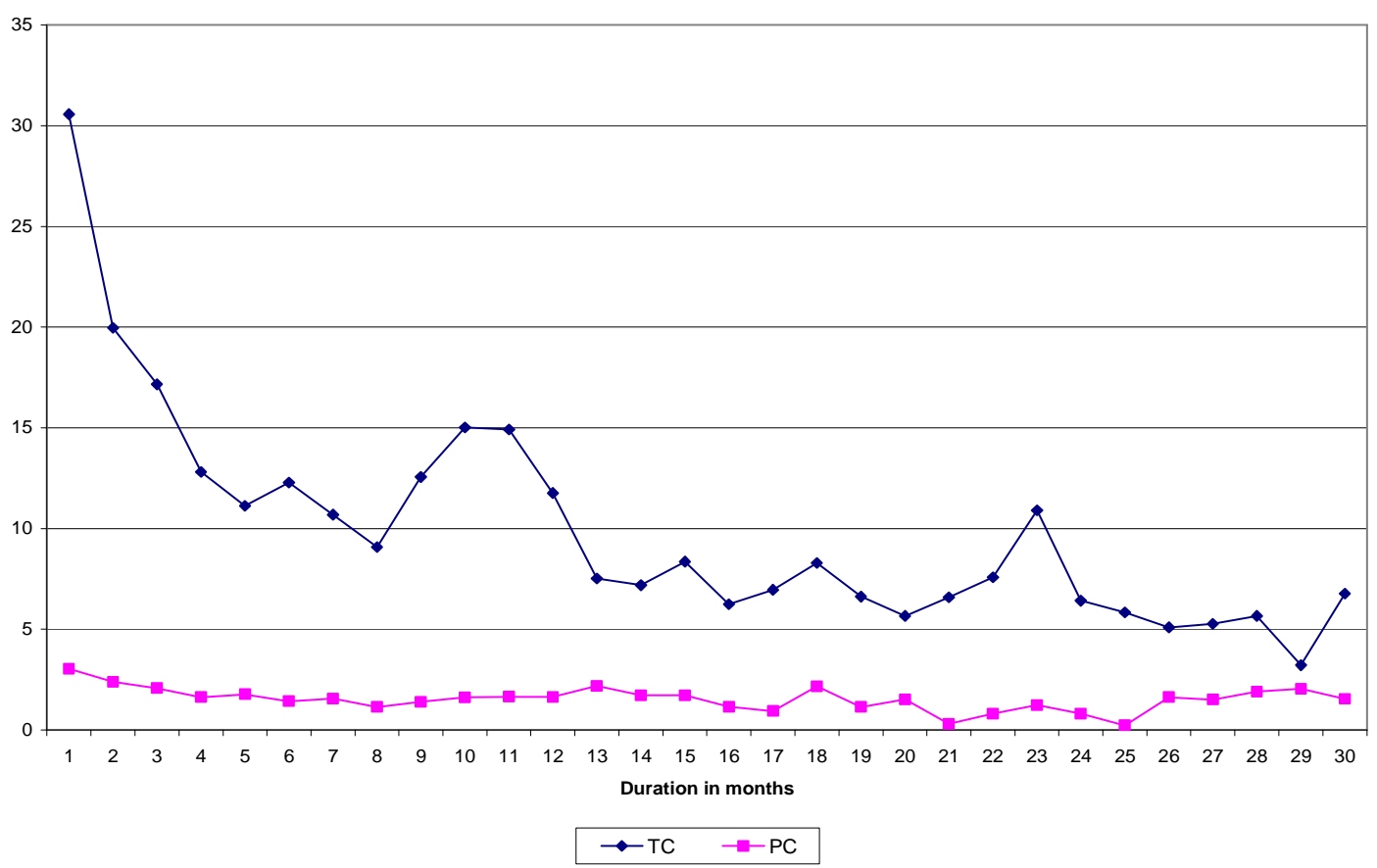


Figure 4.1.Empirical hazard rate from TC. Kaplan Meier estimates. Low Qualification group

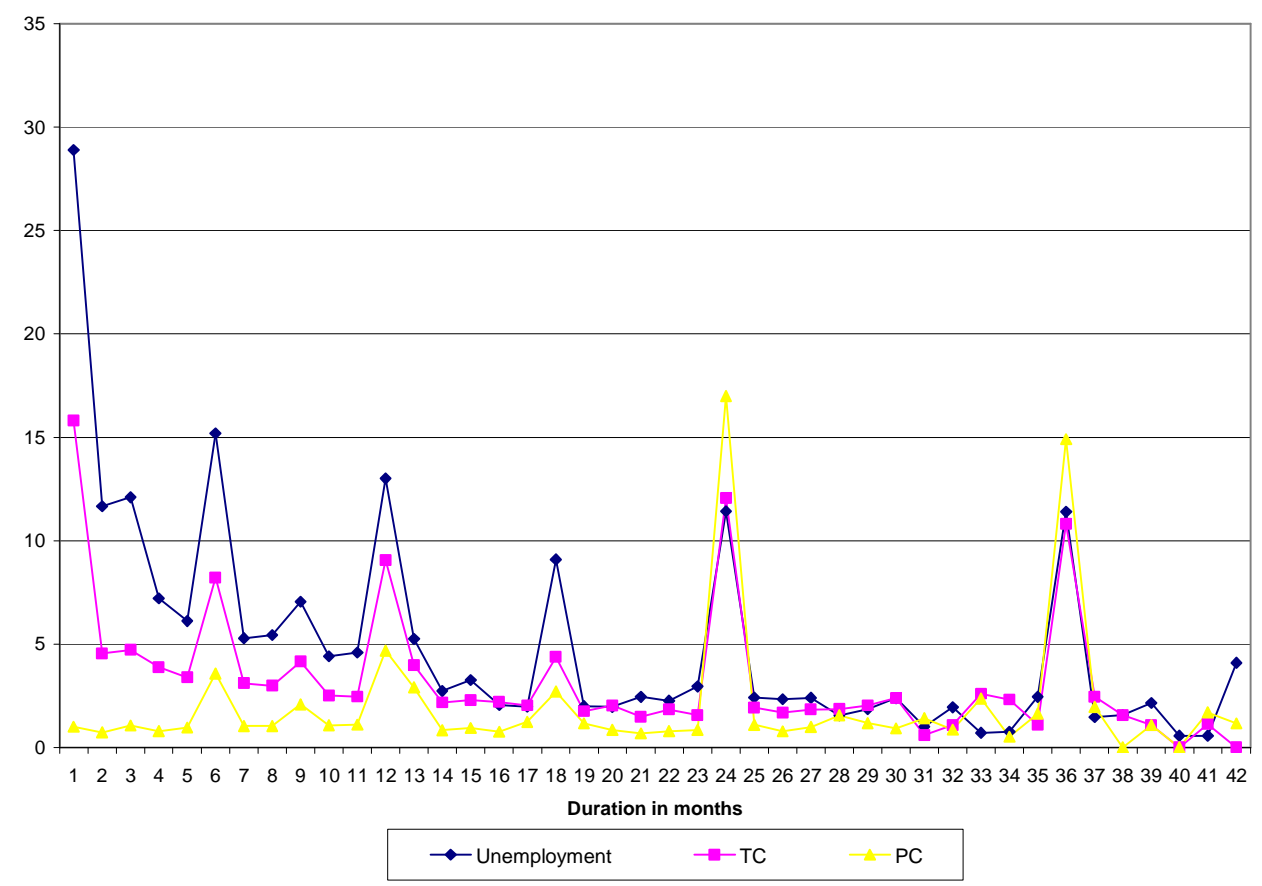

Figure 4.2. Empirical hazard rate from Unemployment. Kaplan Meier estimates. Low Group

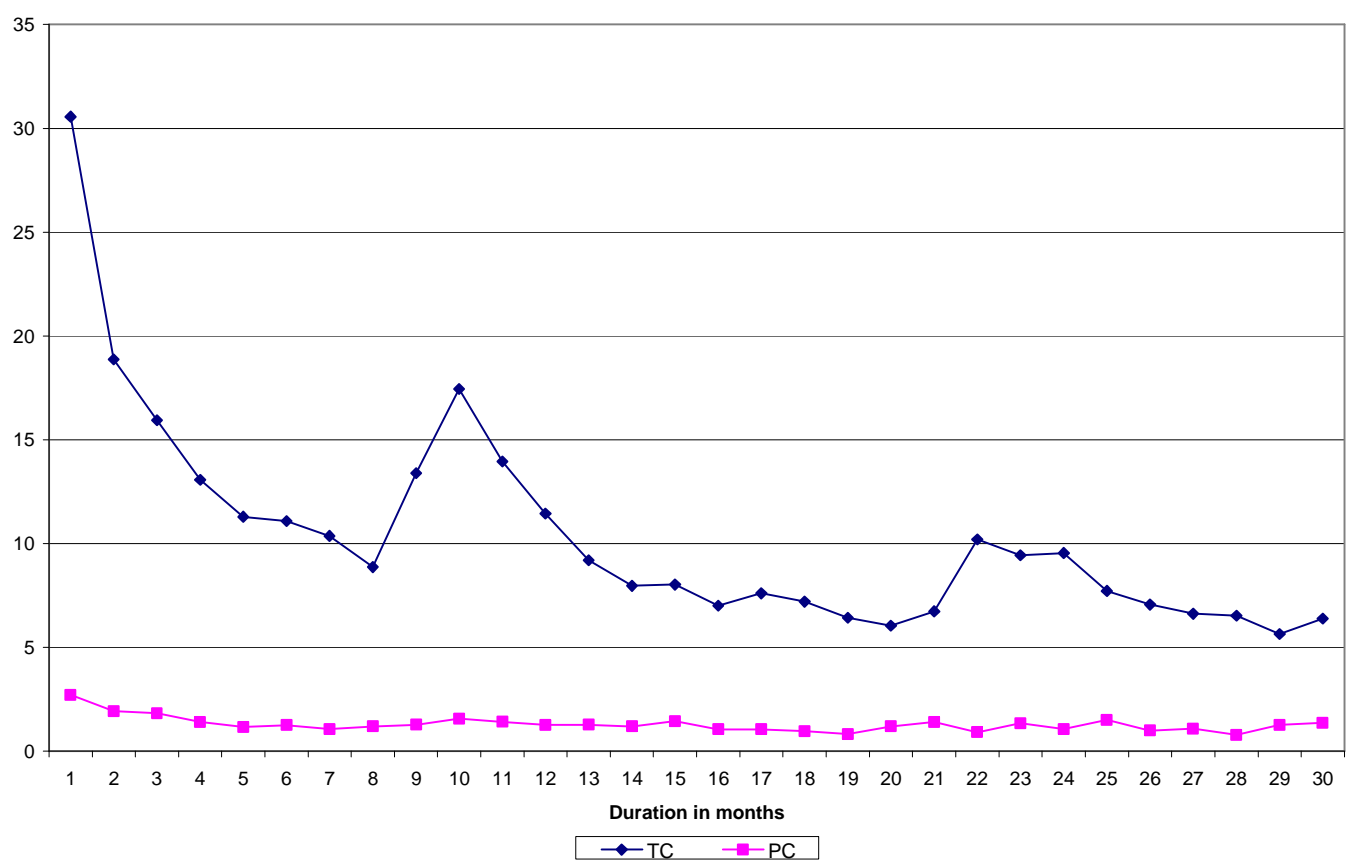


Figure 5.1. Predicted hazard from TC by type of individuals. High qualification group

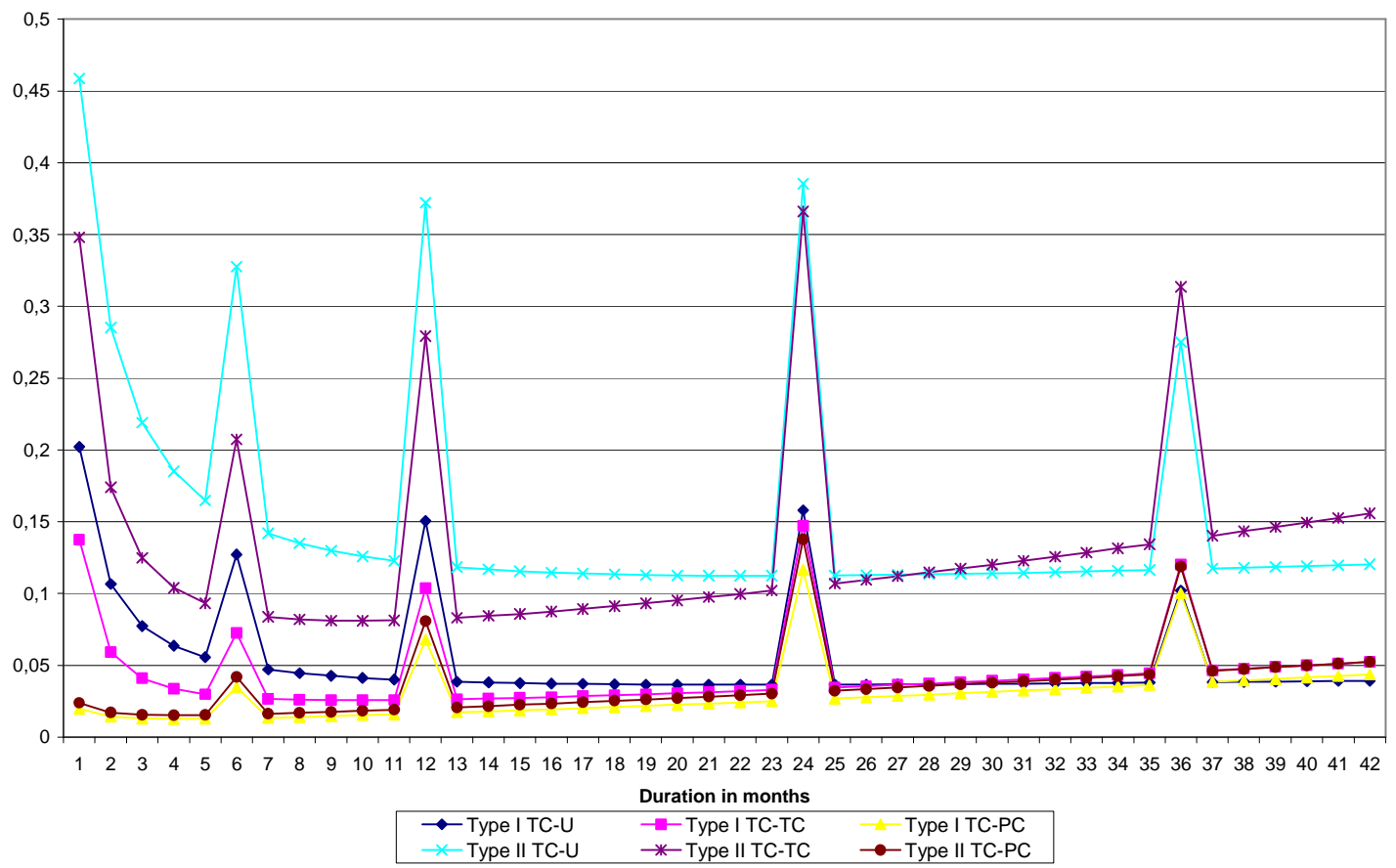

Figure 5.2. Predicted hazard from unemployment by type of individuals. High qualification group

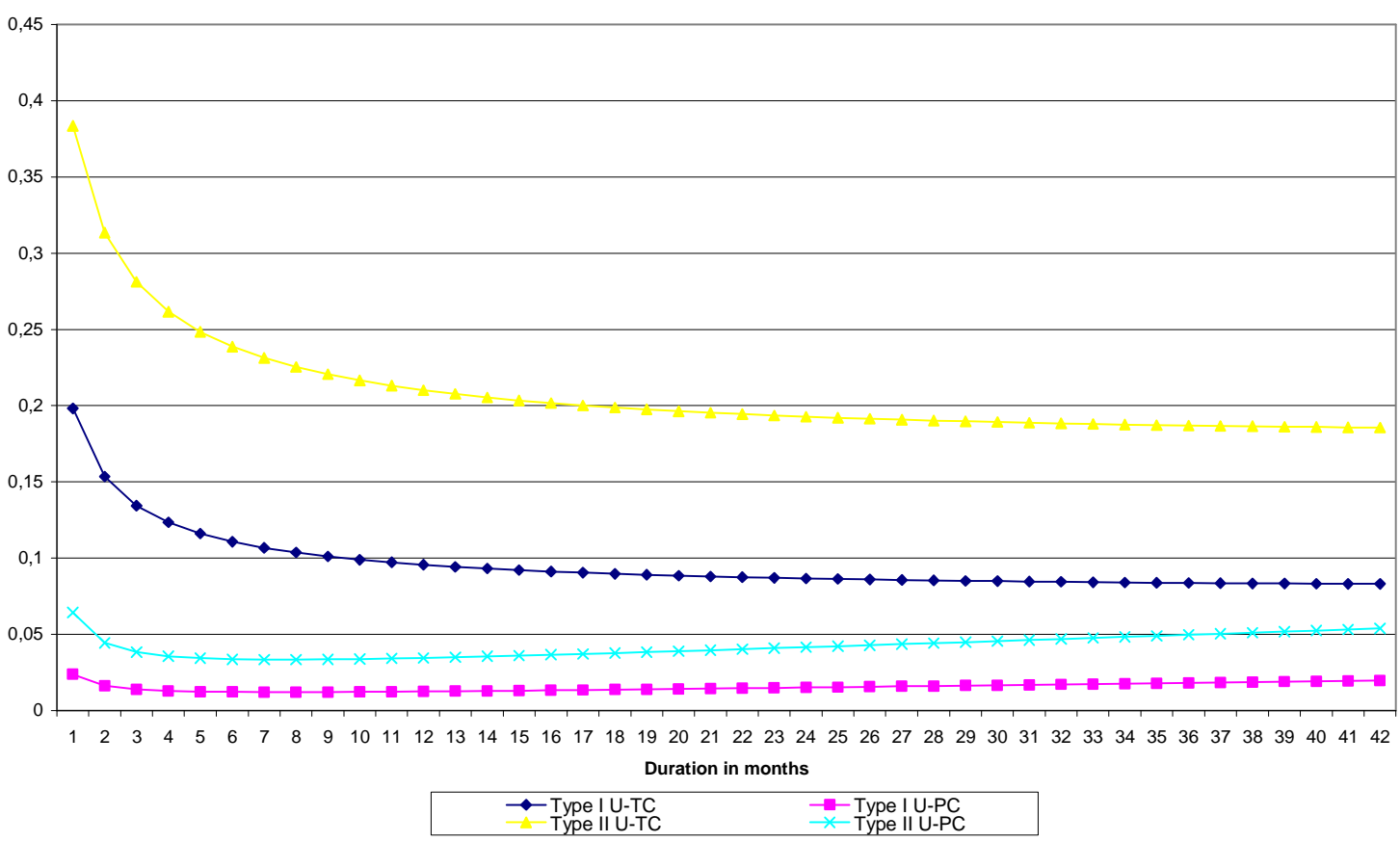


Figure 6.1. Predicted hazard from employment by type of individuals. Medium qualification group

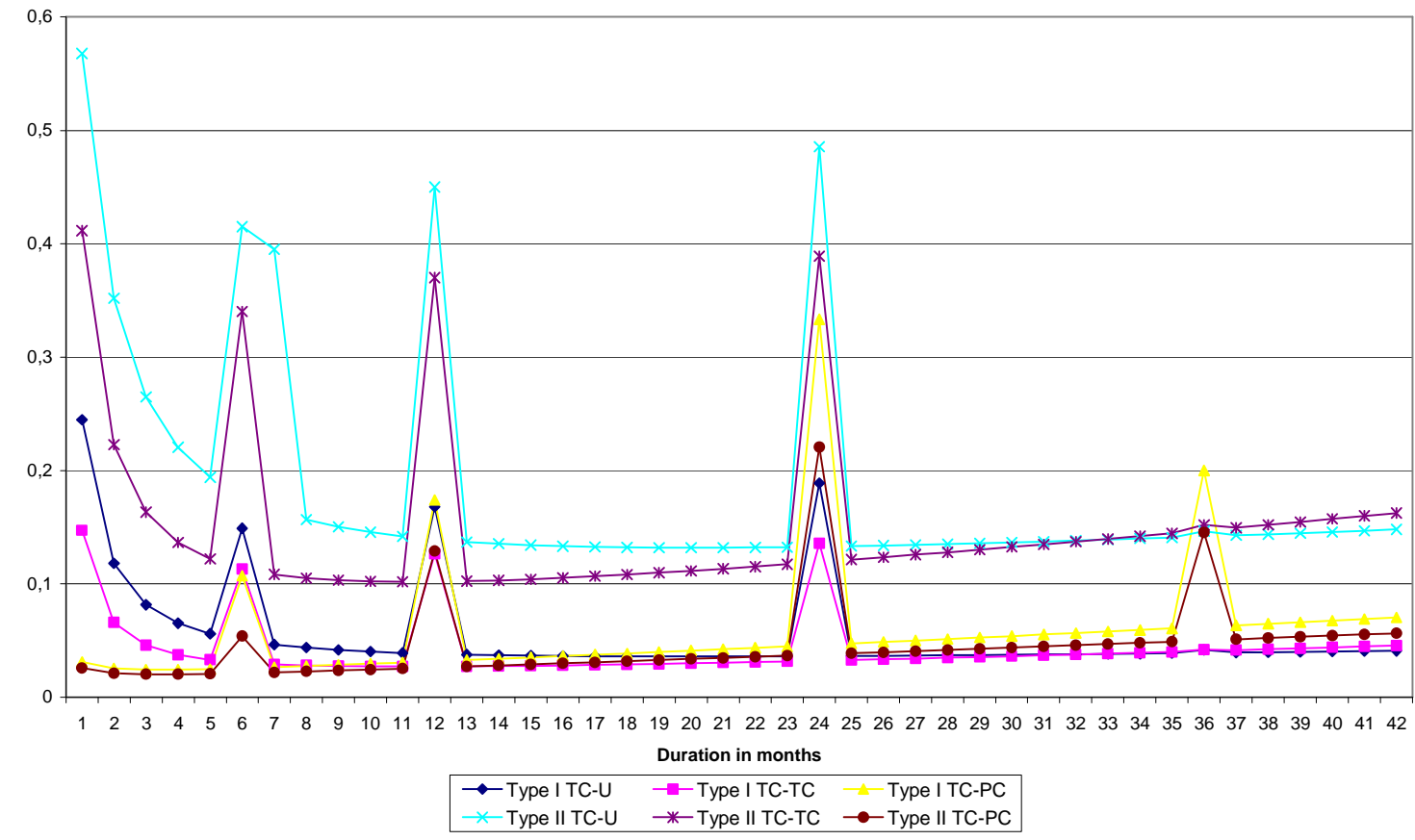

Figure 6.2. Predicted hazard from unemployment by type of individuals. Medium qualification group

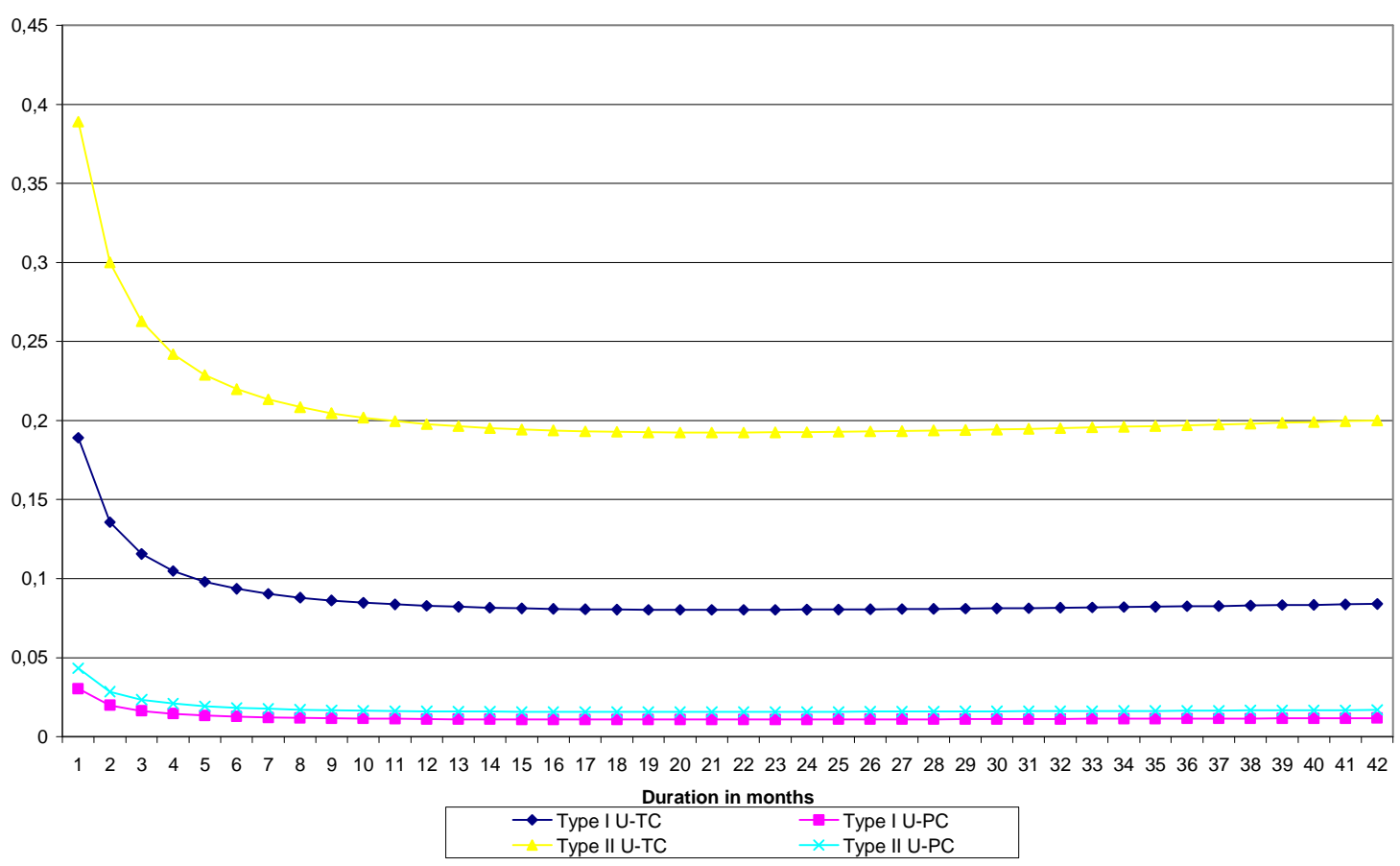


Figure 7.1. Predicted hazard from employment by type of individuals. Low qualification group

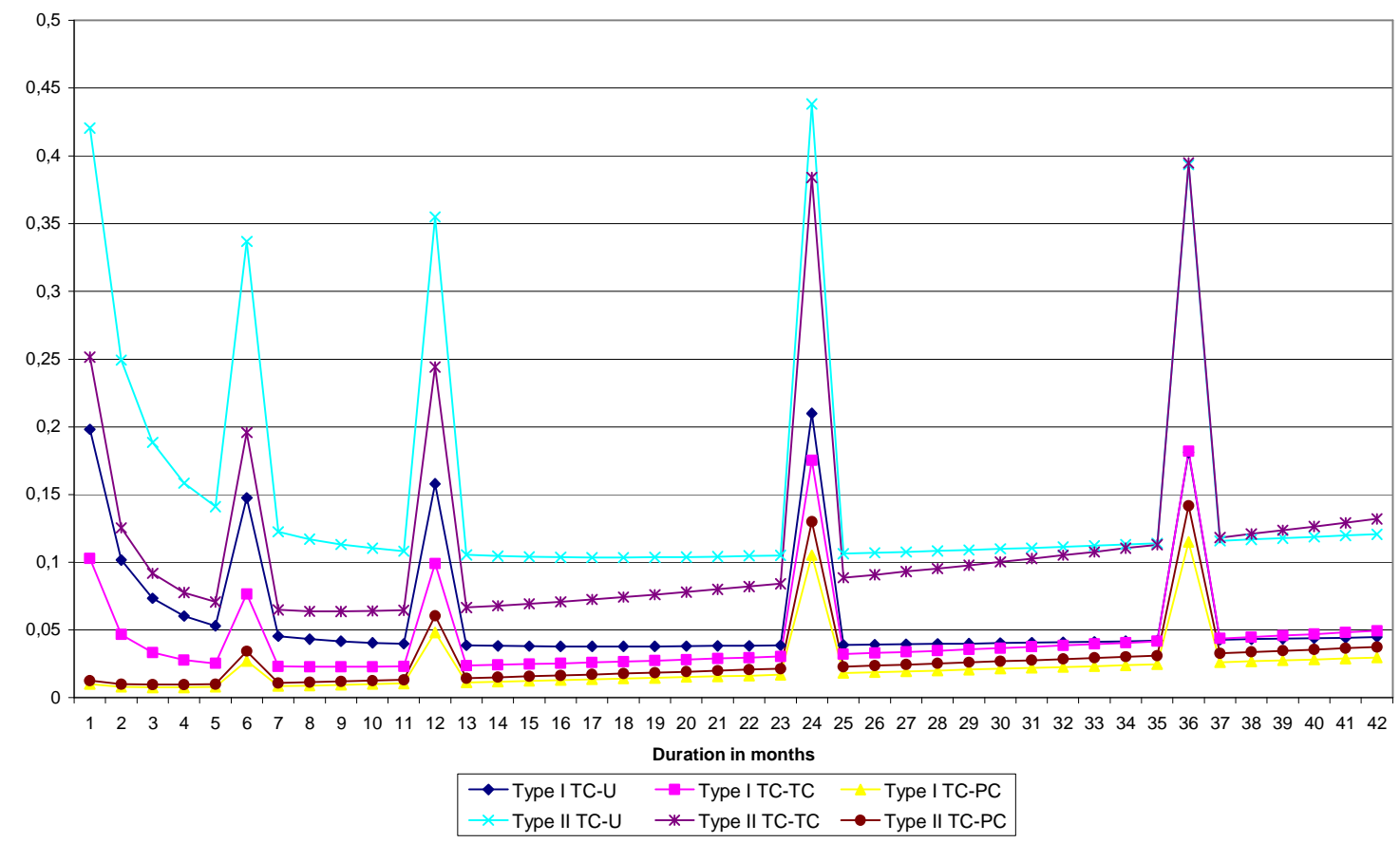

Figure 7.2. Predicted hazard from unemployment by type of individuals. Low qualification group

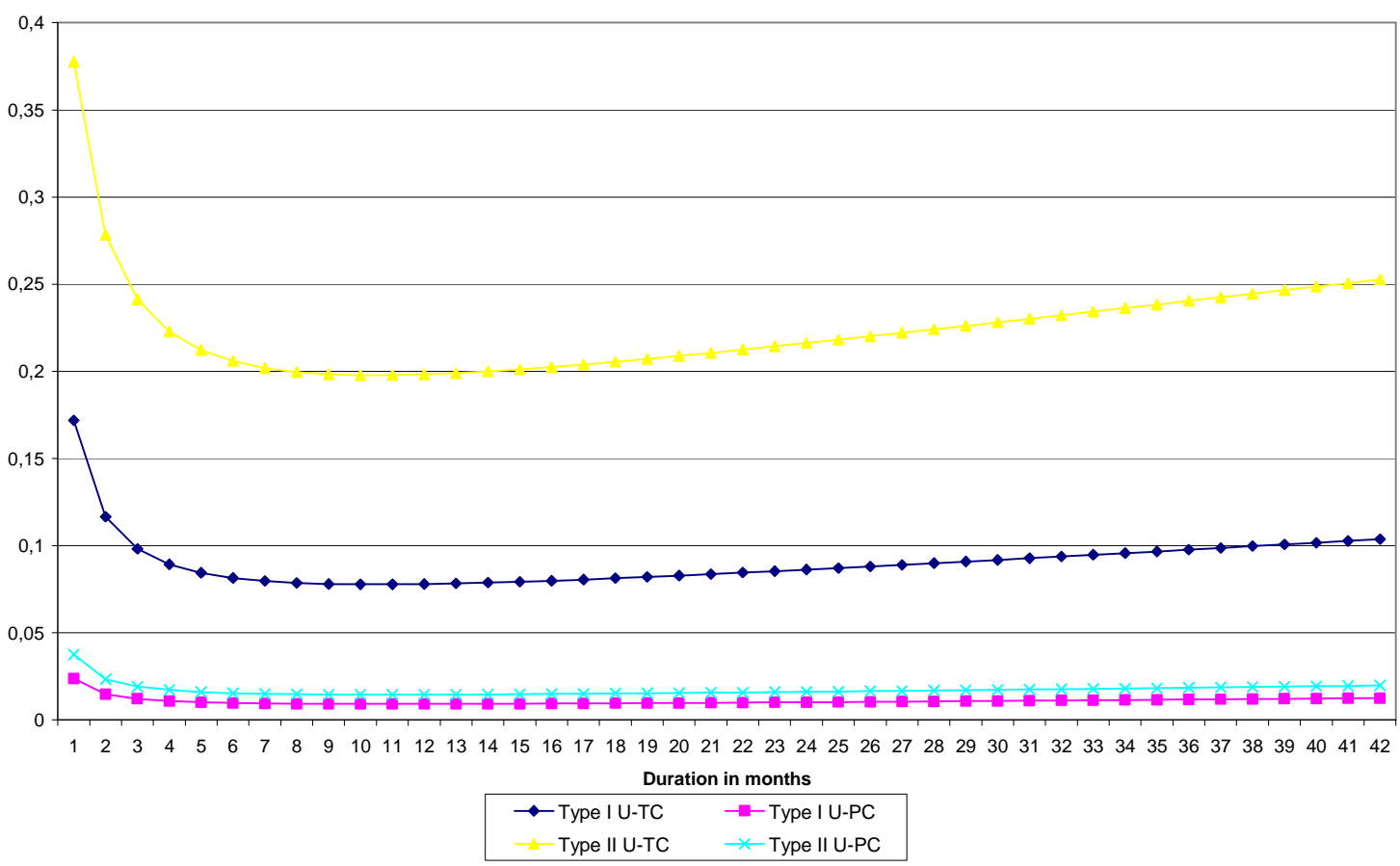

